\title{
Interventions for preventing falls in people after stroke (Review)
}

Verheyden GSAF, Weerdesteyn V, Pickering RM, Kunkel D, Lennon S, Geurts ACH, Ashburn

A
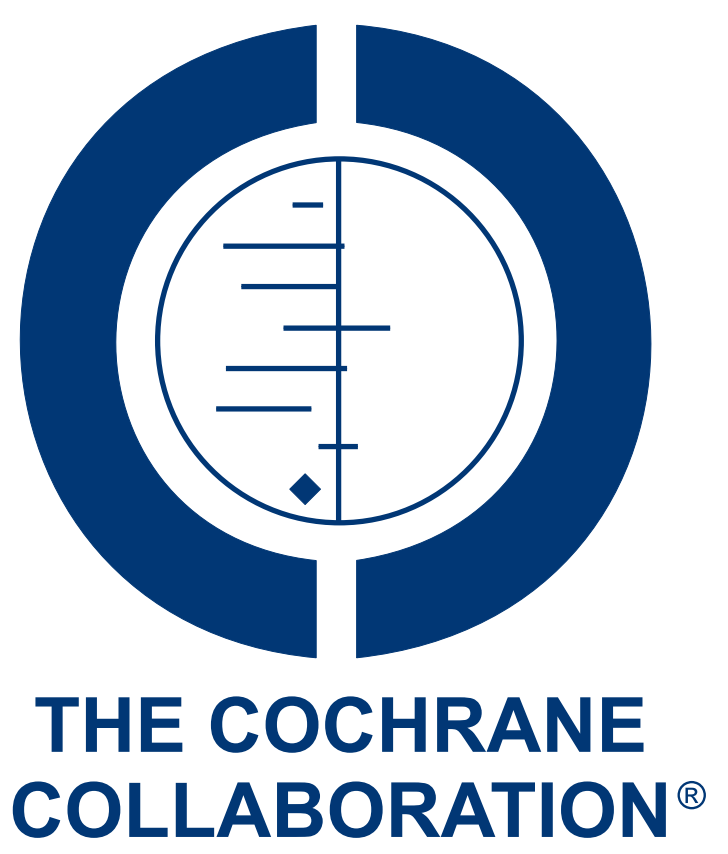

This is a reprint of a Cochrane review, prepared and maintained by The Cochrane Collaboration and published in The Cochrane Library 2013, Issue 5

http://www.thecochranelibrary.com

\section{WILEY}

Interventions for preventing falls in people after stroke (Review)

Copyright $\odot 2013$ The Cochrane Collaboration. Published by John Wiley \& Sons, Ltd. 
TABLE OF CONTENTS

HEADER . . . . . . . . . . . . . . . . . . . . . . . . . . . . . . . . . . . . 1

ABSTRACT . . . . . . . . . . . . . . . . . . . . . . . . . . . . . . . . . . . . . . . . . . . .

PLAIN LANGUAGE SUMMARY . . . . . . . . . . . . . . . . . . . . . . . . . . . . . . . . . . . . . . . . .

BACKGROUND . . . . . . . . . . . . . . . . . . . . . . . . . . . . . . . . . . . . . .

OBJECTIVES . . . . . . . . . . . . . . . . . . . . . . . . . . . . . . . . . . . . . . . . . . . .

METHODS . . . . . . . . . . . . . . . . . . . . . . . . . . . . . . . . . . . . . .

RESULTS . . . . . . . . . . . . . . . . . . . . . . . . . . . . . . . . . . 6

Figure 1. . . . . . . . . . . . . . . . . . . . . . . . . . . . . . . . . . . . . 7

Figure 2. . . . . . . . . . . . . . . . . . . . . . . . . . . . . . . . . . . . . . . . . . 9

Figure 3. . . . . . . . . . . . . . . . . . . . . . . . . . . . . . . . . . . . . 10

DISCUSSION . . . . . . . . . . . . . . . . . . . . . . . . . . . . . . . . . . . . . .

AUTHORS' CONCLUSIONS . . . . . . . . . . . . . . . . . . . . . . . . . . . . . . . . . . . . . 15

ACKNOWLEDGEMENTS . . . . . . . . . . . . . . . . . . . . . . . . . . . . . . . . . . . . . . . . 16

REFERENCES . . . . . . . . . . . . . . . . . . . . . . . . . . . . . . . . . . . . . . 16

CHARACTERISTICS OF STUDIES . . . . . . . . . . . . . . . . . . . . . . . . . . . . . . . . . . . . . . . . .

DATA AND ANALYSES . . . . . . . . . . . . . . . . . . . . . . . . . . . . . . . . . . . . 32

Analysis 1.1. Comparison 1 Exercise, Outcome 1 Rate of falls. . . . . . . . . . . . . . . . . . . . . . . . . . . 33

Analysis 1.2. Comparison 1 Exercise, Outcome 2 Number of fallers. . . . . . . . . . . . . . . . . . . . . . . . 34

Analysis 2.1. Comparison 2 Environment: single lens distance glasses versus usual (multifocal) glasses, Outcome 1 Rate of falls.

Analysis 2.2. Comparison 2 Environment: single lens distance glasses versus usual (multifocal) glasses, Outcome 2 Number of fallers. . . . . . . . . . . . . . . . . . . . . . . . . . . . . . . . . . . . . . . . . . . . . . . . . . . . . .

APPENDICES . . . . . . . . . . . . . . . . . . . . . . . . . . . . . . . . . . . . 35

CONTRIBUTIONS OF AUTHORS . . . . . . . . . . . . . . . . . . . . . . . . . . . . . . . . . 43

DECLARATIONS OF INTEREST . . . . . . . . . . . . . . . . . . . . . . . . . . . . . . . . . . . . . . 43

DIFFERENCES BETWEEN PROTOCOL AND REVIEW . . . . . . . . . . . . . . . . . . . . . . . . . . . . 43

INDEX TERMS . . . . . . . . . . . . . . . . . . . . . . . . . . . . . . . . . . . . . 43

Interventions for preventing falls in people after stroke (Review)

Copyright $\odot 2013$ The Cochrane Collaboration. Published by John Wiley \& Sons, Ltd. 


\title{
[Intervention Review]
}

\section{Interventions for preventing falls in people after stroke}

\author{
Geert SAF Verheyden ${ }^{1,2}$, Vivian Weerdesteyn ${ }^{3}$, Ruth M Pickering ${ }^{4}$, Dorit Kunkel ${ }^{2}$, Sheila Lennon ${ }^{5}$, Alexander CH Geurts ${ }^{3}$, Ann \\ Ashburn $^{6}$ \\ ${ }^{1}$ Department of Rehabilitation Sciences, KU Leuven, Leuven, Belgium. ${ }^{2}$ Faculty of Health Sciences, University of Southampton, \\ Southampton, UK. ${ }^{3}$ Department of Rehabilitation, Nijmegen Centre for Evidence Based Practice, Radboud University Medical Centre, \\ Nijmegen, Netherlands. ${ }^{4}$ Department of Public Health Sciences and Medical Statistics, University of Southampton, Southampton, \\ UK. ${ }^{5}$ Faculty of Health Sciences, School of Medicine, Flinders University, Adelaide, Australia. ${ }^{6}$ Faculty of Health Sciences, University \\ of Southampton, Southampton, UK
}

Contact address: Geert SAF Verheyden, geert.verheyden@faber.kuleuven.be.

Editorial group: Cochrane Stroke Group.

Publication status and date: New, published in Issue 5, 2013.

Review content assessed as up-to-date: 13 January 2010.

Citation: Verheyden GSAF, Weerdesteyn V, Pickering RM, Kunkel D, Lennon S, Geurts ACH, Ashburn A. Interventions for preventing falls in people after stroke. Cochrane Database of Systematic Reviews 2013, Issue 5. Art. No.: CD008728. DOI: 10.1002/14651858.CD008728.pub2.

Copyright (C) 2013 The Cochrane Collaboration. Published by John Wiley \& Sons, Ltd.

\begin{abstract}
A B S T R A C T
Background

Falls are one of the most common medical complications after stroke with a reported incidence of $7 \%$ in the first week after stroke onset. Studies investigating falls in the later phase after stroke report an incidence of up to $73 \%$ in the first year post-stroke.
\end{abstract}

\section{Objectives}

To evaluate the effectiveness of interventions aimed at preventing falls in people after stroke.

\section{Search methods}

We searched the trials registers of the Cochrane Stroke Group (November 2012) and the Cochrane Bone, Joint and Muscle Trauma Group (May 2012), the Cochrane Central Register of Controlled Trials (CENTRAL) in The Cochrane Library 2012, Issue 5, MEDLINE (1950 to May 2012), EMBASE (1980 to May 2012), CINAHL (1982 to May 2012), PsycINFO (1806 to May 2012), AMED (1985 to May 2012) and PEDro (May 2012). We also searched trials registers, checked reference lists and contacted authors.

\section{Selection criteria}

Randomised controlled trials of interventions where the primary or secondary aim was to prevent falls in people after stroke.

\section{Data collection and analysis}

Review authors independently selected studies for inclusion, assessed trial quality, and extracted data. We used a rate ratio and $95 \%$ confidence interval (CI) to compare the rate of falls (e.g. falls per person year) between intervention and control groups. For risk of falling we used a risk ratio and $95 \%$ CI based on the number of people falling (fallers) in each group. We pooled results where appropriate.

Interventions for preventing falls in people after stroke (Review)

Copyright @ 2013 The Cochrane Collaboration. Published by John Wiley \& Sons, Ltd. 


\section{Main results}

We included 10 studies with a total of 1004 participants. One study evaluated the effect of exercises in the acute and subacute phase after stroke but found no significant difference in rate of falls (rate ratio $0.92,95 \% \mathrm{CI} 0.45$ to $1.90,95$ participants). The pooled result of four studies investigating the effect of exercises on preventing falls in the chronic phase also found no significant difference for rate of falls (rate ratio $0.75,95 \%$ CI 0.41 to $1.38,412$ participants).

For number of fallers, one study examined the effect of exercises in the acute and subacute phase after stroke but found no significant difference between the intervention and control group (risk ratio 1.19, $95 \%$ CI 0.83 to $1.71,95$ participants). The pooled result of six studies examining the effect of exercises in the chronic phase also found no significant difference in number of fallers between the intervention and control groups (risk ratio $1.02,95 \% \mathrm{CI} 0.83$ to $1.24,616$ participants).

The rate of falls and the number of fallers was significantly reduced in two studies evaluating the effect of medication on preventing falls; one study (85 participants) compared vitamin D versus placebo in institutionalised women after stroke with low vitamin D levels, and the other study (79 participants) evaluated alendronate versus alphacalcidol in hospitalised people after stroke.

One study provided single lens distance glasses to regular wearers of multifocal glasses. In a subgroup of 46 participants post-stroke there was no significant difference in the rate of falls (rate ratio $1.08,95 \%$ CI 0.52 to 2.25 ) or the number of fallers between both groups (risk ratio $0.74,95 \%$ CI 0.47 to 1.18 ).

\section{Authors' conclusions}

There is currently insufficient evidence that exercises or prescription of single lens glasses to multifocal users prevent falls or decrease the number of people falling after being discharged from rehabilitation following their stroke. Two studies testing vitamin $\mathrm{D}$ versus placebo and alendronate versus alphacalcidol found a significant reduction in falls and the number of people falling. However, these findings should be replicated before the results are implemented in clinical practice.

\section{PLAIN LANGUAGE SUMMARY}

\section{Interventions for preventing falls in people after stroke}

Falls are commonly seen in people who have had a stroke and occur in $7 \%$ of people in the first week after their stroke. In the later phase after stroke, $55 \%$ to $73 \%$ of people experience a fall one year after their stroke. Not all falls are serious enough to require medical attention but even non-serious falls may lead to people developing a fear of falling. They are a factor for predicting future falls, which may restrict the person's activities of daily living and therefore require attention. This review investigated which methods are effective for preventing falls in people after their stroke. After searching the literature, we included 10 studies with a total of 1004 participants. We found studies that investigated exercises, medication, and the provision of single lens distance vision glasses instead of multifocal glasses for preventing falls. Exercises did not appear to reduce the rate of falls or the number of people falling. The majority of studies asked participants to do exercises only. One study offered exercises together with additional components such as educational sessions about falls. Another study offered exercises together with a comprehensive risk assessment and subsequent referrals, such as a review by an optometrist or new shoes, leading to a personalised programme for preventing falls. Neither of these two studies reduced the rate of falls or the number of people falling. One study, which gave vitamin D to women after their stroke who had low vitamin D levels and were admitted to long-term care, showed a reduction in the rate of falls and the number of people falling. In another study, alendronate led to a reduction in the rate of falls and the number of people falling in people hospitalised after their stroke. More studies of this kind should be done to confirm these findings before the results are implemented into clinical practice. There is no evidence at the moment that single lens distance vision glasses instead of multifocal glasses reduce the rate of falls or the number of people falling. In summary, there is little evidence that interventions for preventing falls in people after stroke are beneficial. The main reason is that there were only a limited number of studies focusing on people after stroke or that included a stroke subgroup in the study. More research in this important area for people after stroke is therefore warranted. 


\section{B A C K G ROU N D}

\section{Description of the condition}

Falls are one of the most common medical complications after stroke (Davenport 1996; Langhorne 2000). A recent study including fall events early after stroke showed an incidence of $7 \%$ in the first week after stroke onset (Indredavik 2008). Incidence figures from studies collecting data between one and six months poststroke vary from 25\% (Indredavik 2008) to 37\% (Kerse 2008). Studies evaluating participants between six and 12 months after stroke report incidences from $40 \%$ (Belgen 2006) to 50\% (Harris 2005). One year after stroke, the reported incidence ranges from 55\% (Ashburn 2008) to 73\% (Sackley 2008). Not all falls are serious enough to require medical attention, but non-serious falls are a known predictor for future falls, and can lead to fear of falling, and may restrict a person's activities of daily living. In summary, serious and non-serious falls are still among the most common complications after stroke and their increasing incidence poses a challenge for rehabilitation.

Many stroke-related impairments contribute to deficits of balance and falls, e.g. muscle weakness, sensory loss, reduced attention, and abnormalities of vision and spatial awareness (Weerdesteyn 2008). A fall is a strong predictor of further falls among people with stroke living in the community. However, all people with residual difficulties following a stroke should be considered at increased risk (Ashburn 2008).

\section{Description of the intervention}

Few researchers have examined fall prevention or management post-stroke, but interventions recommended for the general elderly population who have experienced falls have been utilised. Preliminary evidence shows that task-specific exercise programmes targeting balance and gait deficits can be beneficial, can reduce fall frequency and are thought to drive neural plasticity (Shepherd 2001). Technological advances in assistive devices, such as anklefoot orthosis, walking aids (Kuan 1999) and functional electrical stimulation (Burridge 2007) have also been shown to produce evidence of improved mobility, although the benefits with respect to falls prevention in people who have had a stroke still need to be evaluated in intervention studies (Weerdesteyn 2008).

\section{Why it is important to do this review}

A summary of the evidence is important for informing evidencebased practice, and to identify gaps in research. There are existing reviews on the prevention of falls for older people (Cameron 2012; Gillespie 2012). However, a stroke is a serious condition leading to altered physical, cognitive and psychological impairments specifically related to the problem of falls in this population.
In addition, persistent impairments in the later stages after stroke can contribute to the increasing incidence of falls in people after stroke. It is currently very unclear how much research has been dedicated to examining the effect of interventions specific to falls in connection with stroke. This review therefore focuses specifically on interventions for preventing falls in people after stroke.

\section{O B J E C T I VES}

To evaluate the effectiveness of interventions aimed at preventing falls in people after stroke. Our primary objective was to determine the effect of interventions on the rate of falls (number of falls divided by length of follow-up) and the number of fallers. Our secondary objectives were to determine the effects of interventions aimed at preventing falls on (1) the number of fall-related fractures, (2) the number of fall-related hospital admissions, (3) near-fall events, (4) economic evaluation, (5) quality of life, and (6) adverse effects of the interventions.

\section{METHODS}

\section{Criteria for considering studies for this review}

\section{Types of studies}

We included controlled trials where participants or clusters were randomly allocated. Had any cross-over trials met our inclusion criteria, we would have included the first phase if the order of assignment was determined randomly.

\section{Types of participants}

We included trials with adult participants (over 18 years of age) in the acute, subacute or chronic stage following stroke with a confirmed diagnosis. Diagnosis of stroke comprised ischaemic as well as haemorrhagic events. People in the acute stage after stroke were defined as people admitted to a dedicated stroke unit or acute hospital ward. People in the subacute stage after stroke were people admitted to a rehabilitation ward or clinic after being discharged from an acute ward, or people who received intensive treatment at home, for example early supported discharge. Finally, we defined people in the chronic stage after stroke as people who were discharged from rehabilitation and were living at home or admitted to institutional care.

We included trials reporting an intervention carried out in a mixed sample of participants, including people after stroke, if data were provided separately (i.e. in a subgroup) for people after stroke. 


\section{Types of interventions}

We included any intervention where a stated primary or secondary aim was to prevent falls. We classified the interventions according to the taxonomy developed by the Prevention of Falls Network Europe (ProFaNE) (Lamb 2007; Lamb 2011), which proposes the following categories.

- Exercises (supervised/unsupervised): including gait, balance and functional training; strength/resistance exercises; flexibility exercises (e.g. yoga); 3D training (e.g. Tai Chi, Qi Gong); general physical activity; endurance training or others.

- Medication (drug target): direct action targeted to specific classes of drugs: including antihypertensives, other cardiovascular agents, vitamin $\mathrm{D}$, calcium, other bone health medication, drugs used in diabetes, anti-Parkinson drugs, anti-dementia drugs, antidepressants, antipsychotic/neuroleptic drugs, anxiolytics, hypnotics and sedatives, other central nervous system drugs, urinary antispasmodics or other specified drugs.

- Surgery: including cataract extraction, pacemaker provision, podiatric surgery or intervention, or others.

- Management of urinary incontinence (e.g. assisted toileting, bladder retraining).

- Fluid or nutrition therapy where the basic objective was to restore the volume and composition of the body fluids to normal with respect to water-electrolyte balance (fluid therapy) or to improve the health status of the individual by adjusting the quantities, qualities, and methods of nutrient intake (nutrition therapy).

- Psychological intervention, either individual or in a group, including cognitive (behavioural) intervention, or others.

- Environment/assistive technology, which includes technical aids for people with disabilities.

$\circ$ Environment (furnishings and adaptations to homes and other premises): direct action including dwelling unit indoors (including entrances), dwelling unit outdoors, public outdoor (e.g. pavement) or relocation.

- Environment (aids for personal mobility such as walking aid, wheelchair).

- Environment (aids for communication, information and signalling): including optical aids, hearing aids, aids for signalling and indicating or alarm systems.

- Environment (body-worn aids for personal care and protection): including body-worn protective aids, clothes and shoes, or others.

- Environmental (social environment): including staff ratio, staff training, service model change, telephone support, caregiver training, homecare services, or others.

- Knowledge interventions: including written material, videos, lectures or others.

- Other interventions/procedures.

We classified interventions into single interventions with one component; multiple interventions with more than one component, but the intervention was the same for all participants; and multi- factorial interventions with more than one component and the intervention modified for every participant personally (Lamb 2007). We compared the intervention for preventing falls with no additional treatment (routine care) or with another type of intervention.

\section{Types of outcome measures}

We included only those trials that reported an outcome measure related to the rate of falls or the number of fallers. We included trials where falls were collected either prospectively or retrospectively. We expected to find different definitions of a fall, although a consensus report (Lamb 2005) recommends that a fall should be defined as "an unexpected event in which the participants come to rest on the ground, $\mathrm{fl}$ oor, or lower level."

\section{Primary outcomes}

- Rate of falls.

- Number of fallers.

\section{Secondary outcomes}

- Number of people sustaining fall-related fractures.

- Number of people with fall-related hospital admissions.

- Number of people with near-fall events (typically defined as an occasion on which a person felt that they were about to fall, but did not actually fall) (Stack 1999).

- Economic evaluation.

- Quality of life (including psychological aspects such as fear of falling).

- Adverse events.

\section{Search methods for identification of studies}

See the 'Specialized register' section in the Cochrane Stroke Group module. We searched for reports of relevant trials in all languages. We did not include studies published only in abstract form.

\section{Electronic searches}

We searched the trials registers of the Cochrane Stroke Group (last searched November 2012) and the Cochrane Bone, Joint and Muscle Trauma Group (last searched May 2012). In addition, we searched: the Cochrane Central Register of Controlled Trials (CENTRAL) in The Cochrane Library 2012, Issue 5, MEDLINE (1950 to May 2012) (Appendix 1), EMBASE (1980 to May 2012) (Appendix 2), CINAHL (1982 to May 2012) (Appendix 3), PsycINFO (1806 to May 2012) (Appendix 4), AMED (1985 to May 2012) (Appendix 5), and Physiotherapy Evidence Database (PEDro) (www.pedro.org.au/) (May 2012). 
We developed the MEDLINE search strategy with the help of the Cochrane Stroke Group Trials Search Co-ordinator and adapted it for the other databases.

We also searched the following ongoing trials registers (May 2012): ClinicalTrials.gov (http://clinicaltrials.gov/), Current Controlled Trials (www.controlled-trials.com/), International Clinical Trials Registry Platform Search Portal (http://apps.who.int/trialsearch/), and Stroke Trials Registry (www.strokecenter.org/trials/).

\section{Searching other resources}

In an effort to identify further published, ongoing and planned trials we:

- checked reference lists of relevant articles;

- contacted trialists and researchers in the field;

- used Science Citation Index Cited Reference Search for

forward tracking of important articles.

\section{Data collection and analysis}

\section{Selection of studies}

Two review authors (GV and VW) independently screened the titles, abstracts and descriptors of the records obtained from the electronic searches and excluded obviously irrelevant studies. We obtained the full text of the remaining studies and four authors (GV, VW, SL, and AA) independently assessed these for inclusion based on the review eligibility criteria. We resolved disagreements through discussion and contacted study authors for additional information where required.

\section{Data extraction and management}

Three review authors (GV, VW and SL) independently extracted data on to a pre-tested data extraction sheet. We resolved disagreements through discussion, together with the statistical expert (RP).

\section{Assessment of risk of bias in included studies}

Three review authors (GV, VW and SL) independently assessed risk of bias for the following items of each included trial (Higgins 2011a): sequence generation (randomisation), allocation concealment, blinding of assessors (for falls) and incomplete outcome data and selective outcome reporting. We included one additional risk of bias item: reliable ascertainment of fall/fallers outcome where 'low risk of bias' means ascertainment of outcome via active registration, e.g. falls diary; 'high risk of bias' if ascertainment relied on participants' recall over a longer period of time (more than one month); and 'unclear risk of bias' if ascertainment relied on participants' recall over a short period of time (one month or less) or if method of ascertainment was not described.
We collected this information on the data extraction sheet and resolved disagreements through discussion.

\section{Measures of treatment effect}

We used results reported at one year if these were available for trials that monitored falls for longer than one year, and carried out separate analyses pooling information on rates of falling, and risks of falling once or more within a set time period (preferably a year), following the analyses carried out by Gillespie 2012 .

We used the generic inverse variance method for pooling rate and risk ratios, which were entered according to the information available in the source papers, and we set the software to display results in the original scale. We obtained standard errors of the logarithm of the intervention effect using the method described in section 7.7.7.3 of the Cochrane Handbook when a properly estimated confidence interval for the intervention effect was presented in the study report. We included properly analysed unadjusted intervention effects if they were available; otherwise, we considered incorporating properly analysed adjusted estimates of effect, or calculated estimates of unadjusted effects depending on the validity of obtaining estimates from the information presented in the source report (see Unit of analysis issues). Where necessary, we calculated rate ratio estimates of treatment effect using the method described in section 9.4.8 of the Cochrane Handbook and calculated risk ratios using the methods described in section 9.2.2.

The above analysis was based on that carried out in the Cochrane review of interventions for preventing falls in older people living in the community (Gillespie 2012), and so we anticipated that the same analysis would be appropriate when restricted to studies in people after stroke.

For our secondary outcomes (number of people sustaining fallrelated fractures, number of people with fall-related hospital admissions, number of people with near-fall events, economic evaluation, quality of life and adverse events), we expected limited and heterogeneous results throughout the included studies. We therefore provided a narrative description of these results.

\section{Unit of analysis issues}

We planned to incorporate any cluster-randomised trials that we found according to the advice in the Cochrane Handbook, section 16.3, and any cross-over trials according to section 16.4 .

\section{Dealing with missing data}

We contacted study authors to acquire missing data. We planned a sensitivity analysis for studies with missing data (see Sensitivity analysis) but were unable to include this because of the limited number of included studies. 


\section{Assessment of heterogeneity}

We assessed heterogeneity visually by means of forest plots and by reporting the $\mathrm{I}^{2}$ statistic (Higgins 2003). We carried out analyses of subgroups of studies (in the acute/subacute and chronic phase after stroke) in an attempt to explain heterogeneity by study characteristics. As our search resulted in heterogeneous trials that provided information which could be pooled, we conducted a random-effects meta-analysis incorporating random heterogeneity in intervention effect across studies into the standard error of the effect size, so that our findings can be generalised more widely.

\section{Assessment of reporting biases}

We discuss possible problems in the Discussion section of our review. We minimised reporting bias by using a comprehensive search strategy, by searching for studies in other languages than English, and by searching the grey literature (see Searching other resources).

\section{Data synthesis}

Since the studies we found were of a heterogeneous nature, we performed random-effects meta-analyses in all cases. We pooled results from comparable single, multiple and multifactorial interventions as defined in the Types of interventions section above and as presented in the Results section below.

\section{Subgroup analysis and investigation of heterogeneity}

Based on the results of our review, we presented the effect of interventions for preventing falls in the acute and subacute stages separately from those of people living in the community.
We conducted an investigation of heterogeneity as described in the Assessment of heterogeneity section above.

\section{Sensitivity analysis}

Because of the limited number of included studies, we were unable to perform a sensitivity analysis by initially combining low-bias studies, and then adding in the unclear and high-bias studies to check for noticeable changes in the results.

For the same reason, we did not conduct a sensitivity analysis to explore the effect of prospective/retrospective data collection or the different forms of data ascertainment described in the Assessment of risk of bias in included studies section.

As we found studies that comprised single, multiple and multifactorial interventions, we conducted a sensitivity analysis by omitting multiple and multifactorial interventions from the pooled single interventions.

\section{R E S U L T S}

\section{Description of studies}

\section{Results of the search}

We present the study flow diagram of the results of our searches in Figure 1. Our search strategies identified 5702 records. Removal of duplicates resulted in 4138 records for initial screening. We obtained a total of 32 full-text papers for further screening. 
Figure I. Study flow diagram.

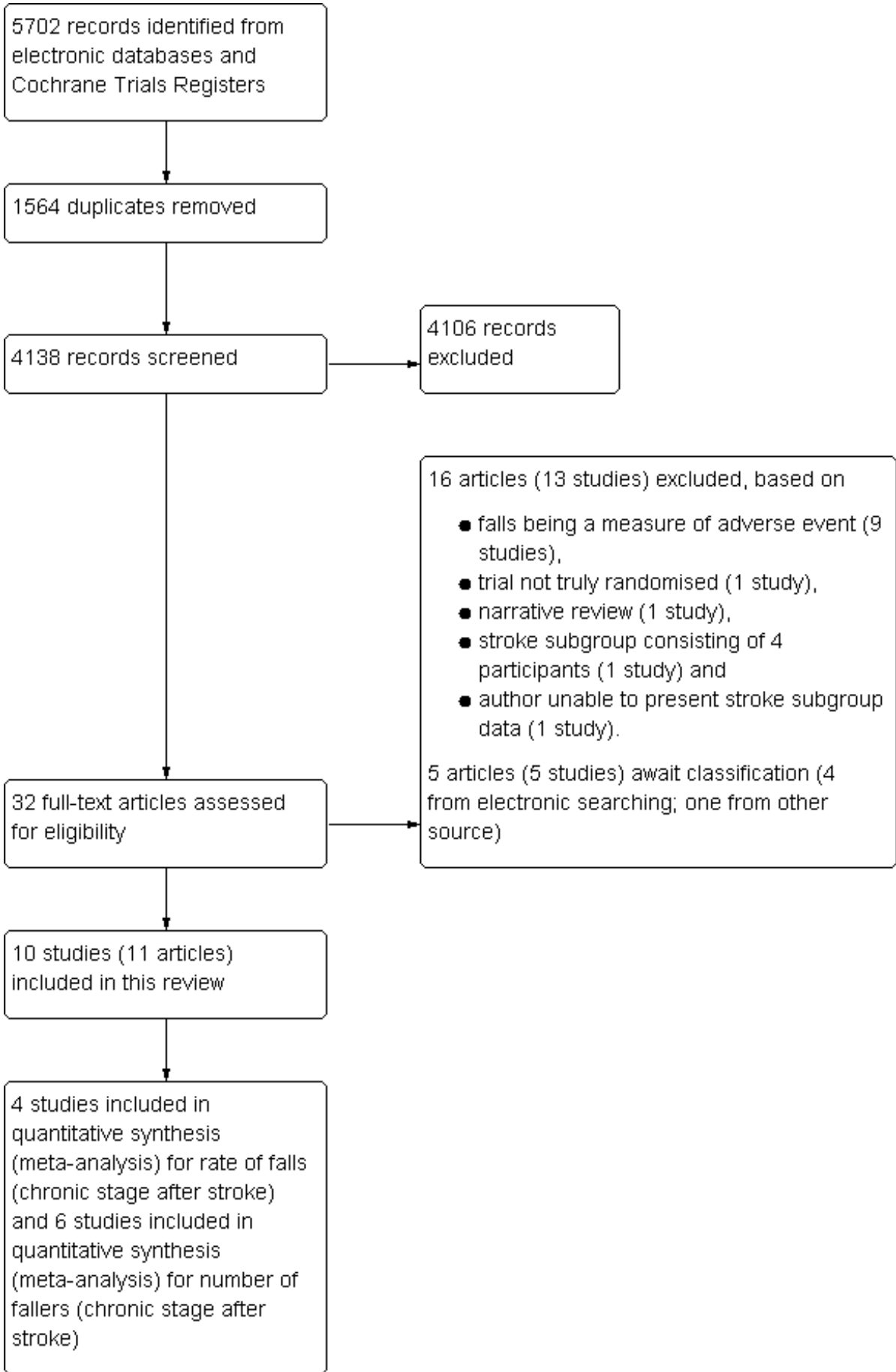




\section{Included studies}

We included 10 studies with a total of 1004 participants. Details of the included studies can be found in the Characteristics of included studies table, and are summarised below.

All studies were individually randomised controlled trials. We did not include any cluster-randomised controlled trials or the first phase of any cross-over trials.

The included studies enrolled between 34 (Holmgren 2010) and 170 (Green 2002) participants, with a median sample size of 119 participants. Age (mean: standard deviation (SD)) of the participants for the experimental and control groups ranged from 57 years (11) (for both groups) in Lau 2012 to 78 years (8) and 79 years (8) respectively in Holmgren 2010. For one study (Lau 2012), the mean age of the participants was under 60 years, two studies (Dean 2012; Marigold 2005) had a mean age between 60 and 69 years, and in the remaining seven studies, the mean age was 70 years or older.

The studies were carried out in six different countries: four in Australia (Batchelor 2012; Dean 2010; Dean 2012; Haran 2010), two in Japan (Sato 2005a; Sato 2011), and one each in Canada (Marigold 2005), Hong Kong (Lau 2012), Sweden (Holmgren 2010) and the UK (Green 2002).

All but one study (Dean 2010) recruited participants in the chronic phase after stroke, with seven studies (Batchelor 2012; Dean 2012; Green 2002; Haran 2010; Holmgren 2010; Lau 2012; Marigold 2005) recruiting people living in the community and two studies (Sato 2005a; Sato 2011) being carried out in an institutional or hospital setting. Dean 2010 recruited participants from an acute and subacute setting.

All but one study (Sato 2005a) included both men and women. Sato 2005a included only women who had suffered a stroke.

Five studies (Dean 2010: Dean 2012; Green 2002; Lau 2012; Marigold 2005) evaluated the effect of exercises on falls. Dean 2010 compared treadmill with overground walking. Dean 2012 investigated the WEBB programme involving task-related training with progressive balance and strengthening exercises as well as walking and stair climbing in comparison with an exercise class for the upper limb. Green 2002 compared community physiotherapy with no intervention. Lau 2012 examined whole-body vibration in comparison with the same exercises without vibration. Marigold 2005 compared agility training with stretching and weight-shifting exercises.

Two studies investigated the effect of medication on falls; Sato 2005a compared vitamin D with placebo and Sato 2011 compared alendronate with alphacalcidol. Haran 2010 examined the effect of single lens distance vision glasses instead of multifocal glasses, and this is classified in the ProFaNE taxonomy under Environment/Assistive technology (aids for communication, information and signalling). Holmgren 2010 evaluated the effect of a multiple intervention that largely consisted of individualised and homebased exercises. Finally, Batchelor 2012 examined the effect of a multifactorial intervention that also partly consisted of an individualised home exercise programme but included a comprehensive risk assessment and referral for a wide range of risk factors. For further details of the interventions provided, see Characteristics of included studies.

In one study (Green 2002), the control group did not receive any intervention. In two studies (Batchelor 2012; Haran 2010), the control group did not receive an additional treatment (usual care only). In all other studies, the control group received the same amount of therapy but another type of treatment, although in the case of Holmgren 2010 the treatment for the control group was not dose-matched to that of the intervention group. For further details of the content of the control group, see the Characteristics of included studies table.

\section{Excluded studies}

From the 32 full-text papers that we screened, we excluded 13 studies (see the Characteristics of excluded studies table). We excluded most of the studies (nine out of 13) because falls were collected as a measure of an adverse event. These studies, therefore, although reporting falls, did not have the aim of preventing them. We excluded Barreca 2004 because the study was not truly randomised, Eng 2010 because it was a narrative review, Halvarsson 2011 because the subgroup of people with stroke consisted of only four participants, and Mayo 1994 because the author was unable to provide us with details and data for the stroke subgroup. Our searching activities did not identify any ongoing trials.

We had insufficient information on four studies, and these await classification. Prior to publication of the review, we identified one additional potential study through contact with an expert: this is also awaiting classification (see the Characteristics of studies awaiting classification table).

\section{Risk of bias in included studies}

For five out of six items of our risk of bias assessment, the majority of our included studies scored as having low risk of bias. Only for blinding of outcome assessment (detection bias) did we score the majority of the included studies as having a high risk of bias. Details of risk of bias assessment for each study are shown in the Characteristics of included studies table. Summary results are shown in Figure 2 and Figure 3. 
Figure 2. Risk of bias summary: review authors' judgements about each risk of bias item for each included study.

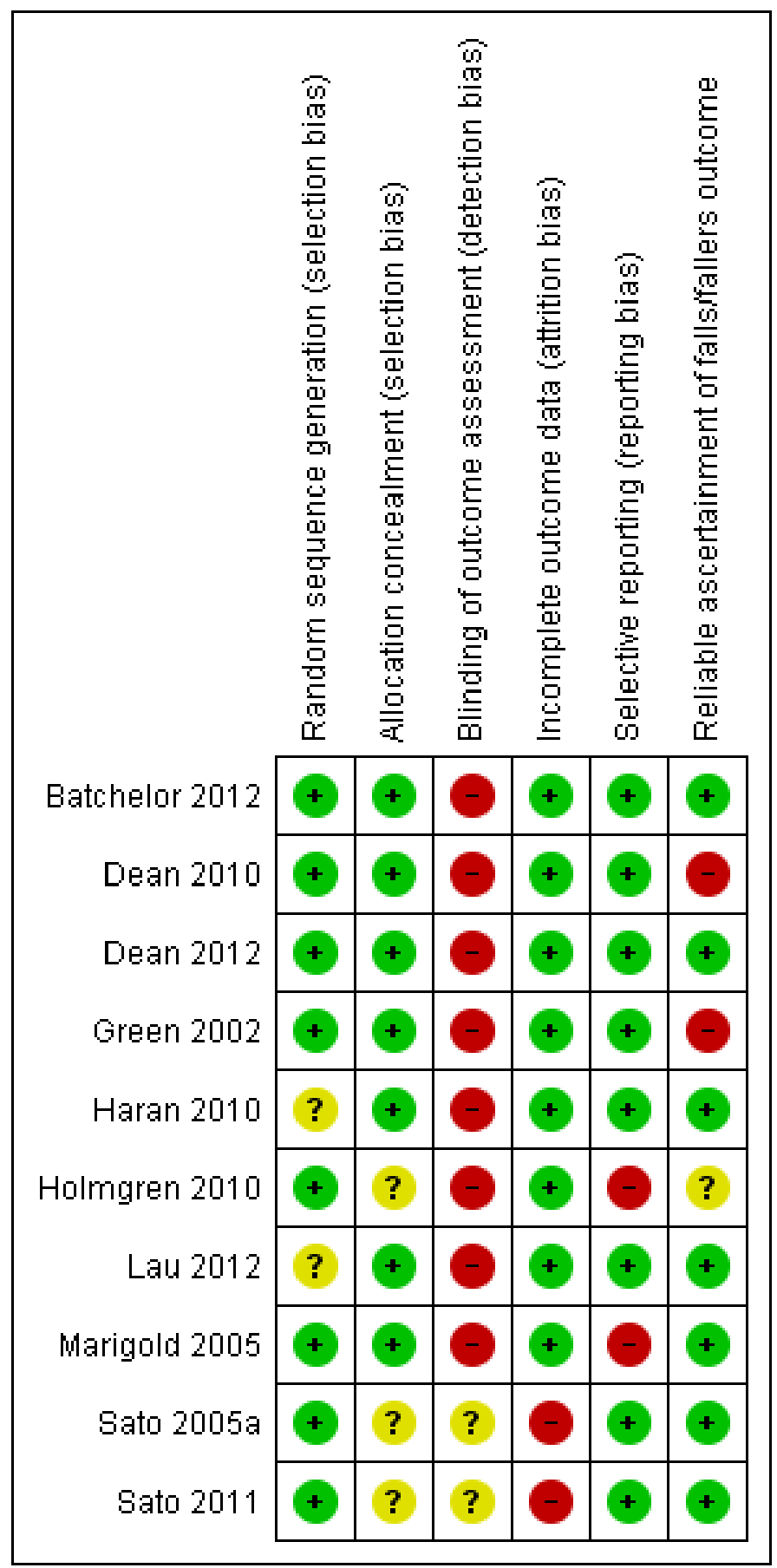

Interventions for preventing falls in people after stroke (Review)

Copyright (๑) 2013 The Cochrane Collaboration. Published by John Wiley \& Sons, Ltd. 
Figure 3. Risk of bias graph: review authors' judgements about each risk of bias item presented as percentages across all included studies.

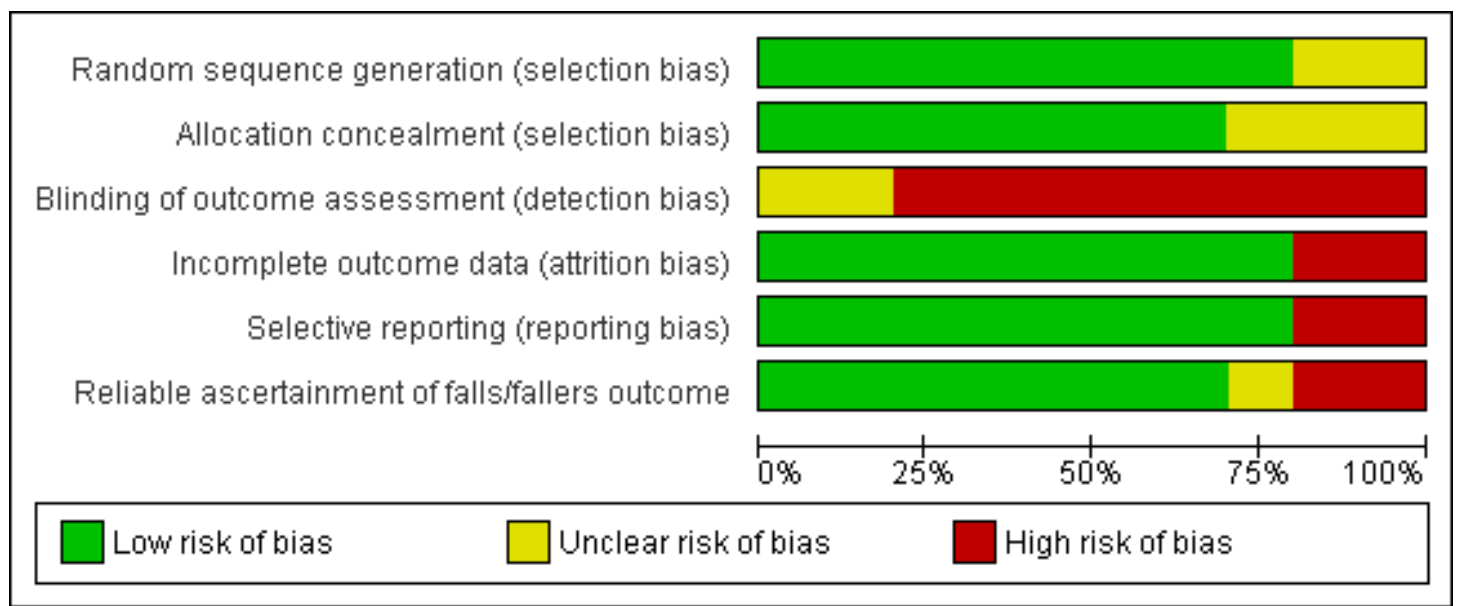

\section{Allocation}

We assessed risk of bias for random sequence generation as low in eight studies $(80 \%)$ and unclear in the remaining two studies (20\%). We assessed risk of bias for allocation concealment as low for seven studies $(70 \%)$ and unclear for the remaining three studies (30\%) (Figure 3).

\section{Blinding}

With participant recall or active registration of falls by the participant themselves through a falls calendar or diary, we assessed the risk of bias for blinding as high in eight studies (80\%) and as unclear in two studies (20\%) (Figure 3). In the latter two studies (Sato 2005a; Sato 2011), falls were recorded by nursing staff filling out standardised fall protocols for institutionalised or hospitalised people after stroke, but nurses recording falls would also be dispensing medication.

\section{Incomplete outcome data}

We scored the risk of bias for incomplete outcome data addressed as low for eight studies (80\%) and high for the remaining two studies (20\%) (Figure 3).

\section{Selective reporting}

We assessed reporting bias as low in eight studies (80\%) and high in the remaining two studies (20\%) (Figure 3).

\section{Other potential sources of bias}

We also assessed whether the falls/fallers outcome was ascertained reliably. For this item, we scored the risk of bias as low for seven studies $(70 \%)$, high for two studies $(20 \%)$ and unclear for the remaining study (10\%) (Figure 3). The seven studies that scored low all used a falls calendar that had to be returned monthly with follow-up telephone calls if necessary. The two studies that scored high (Dean 2010; Green 2002) used retrospective recall of six months and three months respectively. We assessed Holmgren 2010 as being at unclear risk because it was not apparent whether the falls calendar that they used for the six-month follow-up had to be returned monthly, three-monthly or after six months, and if there were any follow-up telephone calls.

\section{Effects of interventions}

\section{Exercises}

Our searches identified five studies that evaluated the effect of exercises on falls (Dean 2010; Dean 2012; Green 2002; Lau 2012; Marigold 2005). As we also identified one multiple trial (Holmgren 2010) and one multifactorial trial (Batchelor 2012) 
where the intervention largely consisted of an exercise component, we decided to include these two studies under the heading 'Exercises' and combine them with those examining the effect of exercises as a single intervention.

\section{Rate of falls}

Data used for this section were based on mean difference reported in Dean 2010, incidence rate ratio reported in Batchelor 2012 and Dean 2012, and incidence rate ratio calculated by the review authors in Lau 2012 and Marigold 2005. No data on falls were obtained from Green 2002 or Holmgren 2010.

\section{Acute/sub-acute stage}

The results for falls in Dean $2010(\mathrm{~N}=95)$ showed that there was a nonsignificant difference in rate of falls between the intervention and the control group (rate ratio $0.92,95 \%$ CI 0.45 to 1.90 ; Analysis 1.1).

\section{Chronic stage}

We pooled the results of four studies (Batchelor 2012; Dean 2012; Lau 2012; Marigold 2005), including 412 participants (Analysis 1.1 ), giving a nonsignificant difference in the rate of falls (rate ratio $0.75,95 \% \mathrm{CI} 0.41$ to 1.38 ). We were unable to include other trials that included exercises (Green 2002; Holmgren 2010) in this analysis due to the lack of group-specific information on falls.

We did not pool results for rate of falls across both stages because participants in Dean 2010 were hospitalised and in the acute and subacute phase after stroke, whereas the other trials included community-dwelling people in the chronic phase after stroke.

When omitting the multifactorial study by Batchelor 2012, our sensitivity analysis of single interventions resulted in a nonsignificant difference in rate of falls (rate ratio $0.65,95 \%$ CI 0.31 to 1.37).

\section{Number of fallers}

Data for this section were based on the risk difference reported by Dean 2010, the risk ratio reported by Batchelor 2012 and Dean 2012 , and the risk ratio calculated by the review authors in Green 2002, Holmgren 2010, Lau 2012 and Marigold 2005.

\section{Acute/sub-acute stage}

Dean $2010(\mathrm{~N}=95)$ indicated that there was a nonsignificant difference in the number of fallers between the intervention and control groups (risk ratio $1.19,95 \%$ CI 0.83 to 1.71; Analysis $1.2)$.

\section{Chronic stage}

We pooled the results of six studies (Batchelor 2012; Dean 2012; Green 2002; Holmgren 2010; Lau 2012; Marigold 2005) with a total of 616 participants (Analysis 1.2). This demonstrated a nonsignificant difference in the number of fallers (risk ratio 1.02, 95\% CI 0.83 to 1.24 ).

We decided against pooling results for number of fallers across both stages after stroke, for the reasons stated above.

When omitting the multiple study by Holmgren 2010 and multifactorial study by Batchelor 2012, our sensitivity analysis of single interventions resulted in a nonsignificant difference in the number of fallers (risk ratio $1.10,95 \%$ CI 0.86 to 1.41 ).

\section{Number of people sustaining fall-related fractures}

Three studies reported on participants sustaining fall-related fractures. Dean 2012 indicated that one person had a stroke, fractured his shoulder and died in hospital. Lau 2012 reported that none of the falls resulted in any injuries that required medical attention. Finally, one person in the agility group in Marigold 2005 sustained a hip fracture, but on a task that was included in both programmes.

\section{Number of people with fall-related hospital admissions}

Only Lau 2012 indicated that none of the falls resulted in any injuries that required medical attention.

\section{Number of people with near-fall events}

No study that evaluated the effect of exercises reported on the number of people with near-fall events.

\section{Economic evaluation}

No study that investigated the effect of exercises reported an economic evaluation.

\section{Quality of life}

Every trial reported on quality of life outcomes. Batchelor 2012 used the Falls Efficacy Scale, Swedish modification, but found no significant result in change scores between groups. Dean 2010 investigated community participation with the Adelaide Activities Profile, but found no significant difference between groups. Dean 2012 used the SF-12 version 2 and the Adelaide Activities Profile. No significant results were found for the SF-12, but improvement in the intervention group was noted for the Adelaide Activities Profile - service to others, and improvement in the control group was reported for the Adelaide Activities Profile - social activities. Green 2002 measured the Frenchay Activities Index, Hospital Anxiety and Depression Scale, and General Health Questionnaire 28 , and found no significant differences between groups

Interventions for preventing falls in people after stroke (Review) 
for any of these measures. Holmgren 2010 used the Falls Efficacy Scale - international version (FES-I) and the Frenchay Activities Index. Improvement in the FES-I (compared with baseline) was significantly greater in the intervention group compared with the control group post-intervention and at three-month follow-up. No significant differences were noted for the Frenchay Activities Index. Holmgren 2010 also reported on the SF-36 and showed significant improvement (compared with baseline), for the intervention group, for the SF-36 mental dimension and mental health subscales at three-month follow-up. Both Lau 2012 and Marigold 2005 used the Activities-specific Balance Confidence (ABC) scale but neither study found a significant between-group difference. Marigold 2005 also measured the Nottingham Health Profile and found no difference in outcome between groups.

\section{Adverse events}

Two trials reported specifically on adverse events. Dean 2012 indicated that no falls or other adverse events occurred during the exercise classes, home programme or assessments. Only one participant withdrew because of the intervention, indicating that the exercises had exacerbated an incontinence problem. In Lau 2012, no severe adverse events were reported by the participants, although three indicated mild dizziness during whole-body vibration therapy, and four had lower-limb soreness and fatigue (two from the whole-body vibration group). The authors reported that all symptoms gradually subsided after the first few sessions of training. As mentioned above, one person in the agility group in Marigold 2005 sustained a hip fracture, but on a task that was included in both programmes.

\section{Medication}

We present results for this section as originally presented by the study authors.

\section{Rate of falls}

Falls were reported both in Sato 2005a and Sato 2011. Sato 2005a indicated that of 158 falls during the two-year follow-up, 22 were in the vitamin D group and 136 in the placebo group. Vitamin D supplementation accounted for a 59\% reduction in falls $(95 \%$ CI $28 \%$ to $82 \%, \mathrm{P}=0.003$ ) after adjustments for the covariates. Sato 2011 reported about 77 falls recorded during the one-year follow-up period, with 10 falls in the alendronate group and 67 in the alphacalcidol group. After adjustments for the covariates, alendronate treatment was associated with a 55\% reduction in falls (95\% CI $25 \%$ to $72 \%, \mathrm{P}=0.0021)$.

\section{Number of fallers}

Sato 2005a indicated that of 158 falls during the two-year followup period, 11 fallers were in the vitamin D group and 33 in the placebo group. This accounted for a risk ratio of 0.6 (95\% CI 0.4 to 0.8 ) in favour of vitamin D. Sato 2011 reported that during the one-year follow-up, five people fell in the alendronate group and 14 in the alphacalcidol group. This resulted in a relative risk of 0.7 (95\% CI 0.5 to 0.9$)$ in favour of alendronate.

\section{Number of people sustaining fall-related fractures}

Sato 2005a reported no hip fractures caused by falls in the vitamin $\mathrm{D}$ group, but four in the placebo group ( $\log$ rank, $\mathrm{P}=0.049$ ). Sato 2011 indicated that no-one sustained a hip fracture in the alendronate group, compared with one person in the alphacalcidol group.

Number of people with fall-related hospital admissions, Number of people with near-fall events, Economic evaluation, Quality of life, Adverse events

No study that examined the effect of medication reported on these outcomes.

\section{Environment/assistive technology}

Results for this section, relating to vision improvement, were based on unpublished data from the stroke subgroup in Haran 2010.

\section{Rate of falls}

There was no significant difference in rate of falls when single lens distance vision glasses replaced multifocal glasses for people after stroke (rate ratio $1.08,95 \%$ CI 0.52 to 2.25 ; Analysis 2.1).

\section{Number of fallers}

There was no significant difference in the number of fallers when single lens distance vision glasses replaced multifocal glasses for people after stroke (risk ratio $0.74,95 \%$ CI 0.47 to 1.18 ; Analysis 2.2).

\section{Number of people sustaining fall-related fractures}

No-one with stroke in the intervention group sustained a fracture, compared with one person in the control group .

\section{Number of people with fall-related hospital admissions}

One person with stroke in the intervention group was admitted to hospital once, compared with one person with stroke in the control group admitted to hospital three times.

\section{Number of people with near-fall events}

There were no reports of near-fall events. 


\section{Economic evaluation}

The data did not allow us to perform an economic evaluation.

\section{Quality of life}

Data from the SF-12 physical and mental component score and Falls Efficacy Scale - International version showed no significant difference between groups.

\section{Adverse events}

There were no reports of adverse events.

\section{DISCUSSION}

This review focused on the effects of interventions for preventing falls in people after stroke, with secondary outcomes examining the number of people sustaining fall-related fractures, the number of people with fall-related hospital admissions, the number of people with near-fall events, economic evaluation, quality of life (including psychological aspects such as fear of falling), and adverse events.

\section{Summary of main results}

Our search strategies resulted in 10 studies being included in this review with a total of 1004 participants. Five studies reported an exercise intervention, two studies the use of medication, one study an environmental adaptation (providing single lens glasses to users of multifocal glasses), one study a multiple intervention, and one study a multifactorial intervention. Since both the multiple and multifactorial intervention largely consisted of an exercise component, both studies were included under 'Exercises'.

\section{Exercises}

For rate of falls, results from one study $(\mathrm{N}=95)$ investigating people in the acute and subacute stages after stroke, and pooled results from four studies $(\mathrm{N}=412)$ investigating people in the chronic stage after stroke did not show a significant reduction in the rate of falls. For the number of fallers, results from one study $(\mathrm{N}=95)$ evaluating people in the acute and subacute stages after stroke, and pooled results from six studies $(\mathrm{N}=616)$ evaluating people in the chronic stage after stroke also did not show a significant difference in the number of fallers between both groups. Results for secondary outcome measures were sparse, with the exception of quality of life, but because of the heterogeneity of outcome measures used we decided not to pool these results. Studies assessing the effect of exercises on preventing falls included a total of 12 measures of quality of life. In three of these measures, a significant improvement was reported in favour of the intervention group.

\section{Medication}

Vitamin D was shown to reduce the rate of falls and the number of fallers in one study $(\mathrm{N}=85)$ in institutionalised women with low vitamin D levels in the chronic phase after stroke. In another study in hospitalised people in the chronic stage after stroke $(\mathrm{N}=$ 79), alendronate was also shown to reduce the rate of falls and the number of fallers. These significant findings should be considered provisional until data from further studies evaluating these interventions confirm the results.

\section{Environmental adaptation (vision improvement)}

One study assessed the provision of single lens distance vision glasses instead of multifocal glasses to people after their stroke $(\mathrm{N}$ =46), and did not show a significant reduction in the rate of falls nor a difference in the number of fallers between both groups.

\section{Overall completeness and applicability of evidence}

We were only able to include a limited number of trials with a limited number of participants. In comparison, the review evaluating interventions for preventing falls in older people living in the community (Gillespie 2012) included 159 trials with a total of 79,193 participants. Even fewer of the trials presented data required to include them in our analysis of the rate of falls than in the analysis of the number of fallers. Lamb 2005 provided a consensus statement that both outcomes should be provided in trials reporting on interventions evaluating the prevention of falls, and that future trials should include the numbers of both falls and fallers when presenting their results.

There is currently insufficient evidence that exercises reduce falling after stroke. Of interest is the result of Marigold 2005, which is the only trial individually demonstrating a significant difference between an intervention programme of agility exercises with a control programme that focused on slow and low-impact stretching and weight-shifting exercises. It should be noted that there is a difference for the analysis and subsequent result between Marigold 2005 and our review. In Marigold 2005, the number of falls and the number of fallers were analysed with a Mann-Whitney U test and $\mathrm{CChi}^{2}$ test respectively, and showed no significant betweengroup difference. Based on the information from Marigold 2005, we were able to calculate the parameters of interest for inclusion into our meta-analysis (see Analysis 1.1 and Analysis 1.2). Surprisingly, for the rate of falls (see Analysis 1.1), this resulted in a significant between-group difference in favour of the agility programme. For planning future trials, this trial seems to give an important message about the content of an intervention to prevent 
falls. Furthermore, in the smallest study included in this review (Holmgren 2010), significant improvements in favour of the intervention group were noted in measures of quality of life, including the Falls Efficacy Scale - International version and the SF-36 mental dimension and mental health subscales, even at the threemonth follow-up. For intervention content, which was classified as multiple, the intervention group performed the high-intensity functional exercises (HIFE) programme consisting of (1) individualised exercise sessions including physical activity and functional performance, aimed at improving lower-limb strength, balance and gait ability; (2) implementing the functional exercises into real-life situations; and (3) five one-hour educational sessions with discussions about the increased risk of complications after stroke, such as falls. During the last week of intervention, an individualised home-based exercises programme was designed for each participant. Information from this trial might also be important for planning future trials in this field, but one should remember that differences in the number of fallers were nonsignificant, although it should be noted that the power calculation for Holmgren 2010 was not based on preventing falls but on an improvement of the Berg Balance Scale score.

It should be further noted that some trials reported interesting post hoc analyses. Marigold 2005 showed that for their participants with a history of falls, eight out of 15 continued to fall in the intervention group compared with 13 out of 15 in the control group ( $\mathrm{P}$ $=0.05$ ). Dean 2012 indicated fewer falls in the intervention group for their fast walkers but more falls in the intervention group for their slower walkers. Both studies contribute to the current belief that interventions should be developed for specific subgroups of people with stroke. Again, this information can contribute to the future development of interventions for preventing falls in people after stroke.

As well as the larger number of studies included in the review investigating interventions for preventing falls in the elderly living in the community (Gillespie 2012), there is another contrast with our results: multiple-component group exercises, Tai Chi, and individually prescribed multiple-component home-based exercises did show a beneficial effect for reducing the rate of falls and the risk of falling in this population. We should be cautious, however, considering whether these interventions might be suitable for preventing falls in people after stroke. Two recent trials included in this review (Batchelor 2012; Dean 2012) examined the effect of an intervention containing an exercise programme developed for older people: the Otago Exercise Program (OEP) in Batchelor 2012 and the Weight-bearing Exercise for Better Balance (WEBB) programme in Dean 2012. Neither trial showed significant between-group differences for reducing the rate of falls and the number of fallers, indicating that specific interventions may be required for preventing falls in people after stroke, with strategies aimed at particular deficits that people have after their stroke.

\section{Quality of the evidence}

The causes of falls in people after stroke are complex, and a trial aimed at preventing falls requires a complex intervention. We assessed the majority of trials included in this review as having a low risk of selection, attrition and reporting biases, as well as a reliable ascertainment of falls/fallers outcome (see Figure 3). Of concern was the level of detection bias (blinding of outcome assessment for falls). In the majority of trials (80\%), we assessed this as being at high risk of bias, as studies used a self reported questionnaire or a falls calendar or diary. These methods rely on active registration by the participant, with telephone calls to the participants if (monthly) fall calendars are not returned. Nevertheless, we assessed this as being at high risk of bias, since the assessors, who were in this case the participants themselves, were probably not blinded to group allocation, and because the accuracy of prospective reporting methods may lead to over-or under-reporting of falls (Lamb 2005). Kunkel 2011, comparing retrospective interviews and prospective falls diaries over a 12 -month period in a cohort of 122 people with stroke, found an $83 \%$ agreement between the methods in the classification of fallers. Yet frequent repeat fallers reported falls during the retrospective interview but did not record all falls in the diary. Excluding these outliers, a similar number of falls were reported using either method. Our results for detection bias and the findings from Kunkel 2011 indicate that monitoring falls accurately in a chronic, community-dwelling population remains difficult. Although prospective methods are considered preferable (Hauer 2006), future trials could include both retrospective and prospective methods. Nevertheless, preliminary studies investigating novel assessments of falls, such as portable activity monitors, seem warranted for future research.

Another concern arising from the trials included in this review is the definition of falls. Of the 10 trials, only seven provided a definition of a fall and, among these five different definitions were used, with two trials (Sato 2005a; Sato 2011) presenting a definition not referenced to previous literature. Although the content of these different definitions might not be significantly different, uniformity should be sought in future trials evaluating interventions for preventing falls in people after stroke, with a consensual definition of a fall, such as the one developed by the Preventions of Falls Network Europe (Lamb 2005).

Finally, for six out of 10 trials, the primary aim was to prevent falls. For five of the six, a power calculation was also performed based on establishing a reduction in falls/fallers. The single aim of Holmgren 2010 was to prevent falls, but the power calculation was based on finding an increase in the Berg Balance Scale score, leading to a total of 34 participants recruited. The nonsignificant finding for falls and fallers may have resulted from an inadequate sample size for this outcome. Unpublished stroke subgroup results from Haran 2010 should also be interpreted with caution; this analysis is underpowered, since a limited group of the total study sample was selected for our analysis. Future trials need to be of adequate size, with a power calculation based on reasonable estimates of

Interventions for preventing falls in people after stroke (Review) 
effect size, resulting in trials with many more participants. As an example, Marigold 2005 calculated that, based on their fall data, a sample size of 292 participants per exercise group would be required to detect differences for the number of fallers in a future definitive trial. Future trials will probably need to be multicentred and perhaps international.

\section{Potential biases in the review process}

Although we developed comprehensive search strategies for our review, there is still a possibility that we have missed some trials. Nevertheless, as an international group, we are familiar with the work of colleagues from around the world active in the domain of falls after stroke, so we were able to include studies reporting on trials that were only recently completed.

Another potential bias of our review might be that we excluded trials that reported falls as an adverse event. It could be hypothesised that, although falls were included in these trials despite the fact that the interventions were not aimed at preventing them, some of them might actually have a positive effect on falls or the number of fallers, or both.

Furthermore, one could disagree with our inclusion of Lau 2012 and Marigold 2005 in our pooled analysis, as both arms of these trials received an active exercise component. We believe that our decision was justified as, firstly, there is a general mixture of types of control interventions across our studies, and secondly - and more importantly - we believe that the experimental intervention in both these studies was focused on significant aspects of falls prevention. In Lau 2012 the intervention group conducted whole-body vibration exercises; vibration is thought to improve muscle weakness, the latter being an important predictor for falls (Weerdesteyn 2008). Similarly, in Marigold 2005, the aim of the agility exercises in the experimental group was also clearly more related to falls prevention than the stretching and slow, low-impact weight-shifting exercises conducted in the control group.

Finally, although we were able to obtain data from one study where a subgroup of people with stroke was included, we did not use a systematic approach to obtaining falls data for subgroups of participants with a history of stroke in all fall prevention trials. Despite this, there is strong agreement in identified studies between this review and Batchelor 2010, who also reviewed interventions for falls prevention after stroke. It is reassuring that two independent groups reviewing the same topic largely identify the same studies.

\section{Agreements and disagreements with other studies or reviews}

Our search strategy identified one systematic review on the topic of falls prevention after stroke. Batchelor 2010 included 13 studies and their results are in agreement with those of this review. They also found that the only intervention shown to be effective in reducing falls was vitamin D for institutionalised women after stroke with low vitamin D levels (Sato 2005a). However, there is a discrepancy between the studies included in Batchelor 2010 and our review. In Batchelor 2010, the type of interventions included were all those that may affect falls outcome. On that basis, they also included trials in which falls were classified as an adverse event. Their review therefore contains six trials that we have excluded from our review, because we applied the stricter inclusion criterion that interventions had to be aimed at preventing falls. This is an important distinction. Trials evaluating interventions such as very early mobilisation after stroke or early supported discharge include falls as an outcome. However, the aim of these interventions is not to prevent falls but to improve functional outcome. Because (very) early mobilisation or early supported discharge might be associated with an increase in falls, they are included as an outcome measure. We believe that a stricter approach, i.e. including only trials where the aim was to prevent falls, is justified, as otherwise study hypotheses are mixed and results become difficult to interpret.

\section{AUTHORS' CONCLUSIONS}

\section{Implications for practice}

\section{Exercises}

Currently, there is insufficient evidence that exercises, as a single component or integrated into a multiple or multifactorial intervention, significantly reduce falling after stroke. There is also insufficient evidence relating to the prevention of fall-related fractures, fall-related hospital admissions, near-fall events, economic factors, quality of life, or adverse events to inform practice.

\section{Medication}

One study showed that vitamin D reduced falling in institutionalised women in the chronic phase after stroke with low vitamin D levels. Another study showed that alendronate also reduced falling in comparison with alphacalcidol in hospitalised people in the chronic stage after stroke. Both studies need to be replicated before implementation of these interventions can be used in clinical practice.

\section{Environmental adaptation (vision improvement)}

One study provided people with stroke with single lens distance vision glasses instead of multifocal glasses, but did not find a significant decrease in the rate of falls or the number of fallers. 


\section{Implications for research}

This review provides little evidence for the effectiveness of interventions for preventing falls in people after stroke. Further research into this important but complex area is warranted.

Further studies are needed to assess exercises as a single component or part of a multiple or multifactorial programme, with careful consideration of the content of the intervention, taking into account the current knowledge about risk factors for falling after stroke and the possibility that different interventions have to be developed for different subgroups of people after stroke.

It is important to note that only one study included participants in the acute and subacute phase. Future research could focus on the potential of influencing risk factors for falls in people early after stroke, i.e. while still hospitalised, and on the assessment of the long-term effect when people are discharged back into their community.
Further trials assessing medication are needed to confirm previous findings before recommendations for clinical practice can be made.

Studies investigating fall prevention for people after stroke should be adequately powered, provide a standardised definition of a fall from a consensus statement, use appropriate and accurate methods of fall ascertainment, and apply the current standards for analysis and reporting of data, including the CONSORT guidelines.

\section{ACKNOW LEDGEMENTS}

The authors wish to express their sincere gratitude to Sue Forsey and Paula Sands from the University of Southampton, School of Medicine library for conducting the searches. Furthermore, we thank Stephen R Lord for providing us stroke subgroup data from the VISIBLE trial (Haran 2010).

\section{RE F E R E N C E S}

\section{References to studies included in this review}

Batchelor 2012 \{published data only\}

Batchelor F, Hill K, Mackintosh S, Said C, Fryer C, Whitehead C. Falls prevention after stroke: does adherence to exercise influence falls?. Neurorehabilitation and Neural Repair 2012;26(6):735.

Batchelor F, Hill K, Mackintosh S, Said C, Whitehead

C. Does a multifactorial falls prevention programme reduce falls in people with stroke returning home after rehabilitation? A randomised controlled trial. International Journal of Stroke 2010;5:17.

* Batchelor FA, Hill KD, Mackintosh SF, Said CM, Whitehead $\mathrm{CH}$. Effects of a multifactorial falls prevention programme for people with stroke returning home after rehabilitation: a randomised controlled trial. Archives of Physical Medicine and Rehabilitation 2012;93(9):1648-55. [DOI: 10.1016/j.apmr.2012.03.031]

Batchelor FA, Hill KD, Mackintosh SF, Said CM, Whitehead $\mathrm{CH}$. The FLASSH study: protocol for a randomised controlled trial evaluating falls prevention after stroke and two sub-studies. BMC Neurology 2009;9:14.

[DOI: 10.1186/1471-2377-9-14]

Dean 2010 \{published data only\}

Ada L, Dean CM, Morris ME. Supported treadmill training to establish walking in non-ambulatory patients early after stroke. BMC Neurology 2007;7:29.

Ada L, Dean CM, Morris ME, Simpson JM, Katrak P. Randomized trial of treadmill walking with body weight support to establish walking in subacute stroke: the MOBILISE trial. Stroke 2010;41(6):1237-42. [DOI: 10.1161/STROKEAHA.109.569483]

* Dean CM, Ada L, Bampton J, Morris ME, Katrak PH, Potts S. Treadmill walking with body weight support in subacute non-ambulatory stroke improves walking capacity more than overground walking: a randomised trial. Journal of Physiotherapy 2010;56(2):97-103.

\section{Dean 2012 \{published data only\}}

Dean CM, Rissel C, Sharkey M, Sherrington C, Cumming RG, Barker RN, et al. Exercise intervention to prevent falls and enhance mobility in community dwellers after stroke: a protocol for a randomised controlled trial. BMC Neurology 2009;9:38. [DOI: 10.1186/1471-2377-9-38]

Dean CM, Rissel C, Sherrington C, Sharkey M, Cumming $\mathrm{R}$, Lord SR, et al.Weight-bearing exercise improves mobility in stroke survivors and may prevent falls in faster walkers. Neurorehabilitation and Neural Repair 2012;26(6):730-1. * Dean CM, Rissel C, Sherrington C, Sharkey M, Cumming RG, Lord SR, et al.Exercise to enhance mobility and prevent falls after stroke: the community stroke club randomised trial. Neurorehabilitation and Neural Repair 2012;26(9): 1046-57. [DOI: 10.1177/1545968312441711]

\section{Green 2002 \{published data only\}}

Green J, Forster A, Bogle S, Young J. Physiotherapy for patients with mobility problems more than 1 year after stroke: a randomised controlled trial. Lancet 2002;359 (9302):199-203.

Haran 2010 \{unpublished data only\}

* Haran MJ, Cameron ID, Ivers IQ, Simpson JM, Lee $\mathrm{BB}$, Tanzer M, et al.Effect on falls of providing single lens distance vision glasses to multifocal glasses wearers: VISIBLE randomised controlled trial. BMJ 2010;340: c2265. [DOI: 10.1136/bmj.c2265] Haran MJ, Lord SR, Cameron ID, Ivers RQ, Simpson JM, Lee BB, et al. Preventing falls in older multifocal glasses wearers by providing single-lens distance glasses: the 
protocol for the VISIBLE randomised controlled trial. BMC

Geriatrics 2009;9:10. [DOI: 10.1186/1471-2318-9-10]

Holmgren 2010 \{published data only (unpublished sought but not used)\}

Holmgren E, Gosman-Hedström G, Lindström B, Wester P. What is the benefit of a high-intensive exercise programme on health-related quality of life and depression after stroke? A randomised controlled trial. Advances in Physiotherapy 2010;12(3):125-33.

* Holmgren E, Lindström B, Gosman-Hedström G, Nyberg

$\mathrm{L}$, Wester P. What is the benefit of a high intensive exercise programme? A randomised controlled trial. Advances in Physiotherapy 2010;12(3):115-24.

\section{Lau 2012 \{published data only\}}

Lau RW, Yip SP, Pang MY. Whole-body vibration has no effect on neuromotor function and falls in chronic stroke. Medicine \& Science in Sports \& Exercise 2012;44(8): 1409-18. [DOI: 10.1249/MSS.0b013e31824e4f8c]

Marigold 2005 \{published data only\} Marigold DS, Eng JJ, Dawson AS, Inglis JT, Harris JE, Gylfadottir S. Exercise leads to faster postural reflexes, improved balance and mobility, and fewer falls in older persons with chronic stroke. Journal of the American Geriatrics Society 2005;53(3):416-23.

Sato 2005a \{published data only\}

Sato Y, Iwamoto J, Kanoko T, Satoh K. Low-dose vitamin $\mathrm{D}$ prevents muscular atrophy and reduces falls and hip fractures in women after stroke: a randomised controlled trial. Cerebrovascular Diseases 2005;20(3):187-92.

Sato 2011 \{published data only\}

Sato Y, Iwamoto J, Honda Y. An open-label trial comparing alendronate and alphacalcidol in reducing falls and hip fractures in disabled stroke patients. Journal of Stroke and Cerebrovascular Diseases 2011;20(1):41-6. [DOI: 10.1016/ j.jstrokecerebrovasdis.2009.10.007]

\section{References to studies excluded from this review}

Barreca 2004 \{published data only\}

Barreca S, Sigouin CS, Lambert C, Ansley B. Effects of extra training on the ability of stroke survivors to perform an independent sit-to-stand: a randomised controlled trial. Journal of Geriatric Physical Therapy 2004;27(2):59-64.

Bernhardt 2008 \{published data only\}

* Bernhardt J, Dewey H, Thrift A, Collier J, Donnan G. A very early rehabilitation trial for stroke (AVERT): phase II safety and feasibility. Stroke 2008;39(2):390-6. [DOI: 10.1161/STROKEAHA.107.492363]

Sorbello D, Dewey HM, Churilov L, Thrift AG, Collier JM, Donnan $\mathrm{G}$, et al.Very early mobilisation and complications in the first 3 months after stroke: further results from phase II of a very early rehabilitation trial (AVERT). Cerebrovascular Diseases 2009;28(4):378-83. [DOI: 10.1159/000230712]

Boysen 2009 \{published data only\}

Boysen G, Krarup L, Zeng X, Oskedra A, Kõrv J, Andersen $G$, et al.ExStroke pilot trial of the effect of repeated instructions to improve physical activity after ischaemic stroke: a multinational randomised controlled clinical trial. BMJ 2009;339:b2810. [DOI: 10.1136/bmj.b2810]

Cadilhac 2011 \{published data only\} Cadilhac DA, Hoffmann S, Kilkenny M, Lindley R, Lalor E, Osborne RH, et al.A phase II multicentered single-blind, randomised, controlled trial of the stroke self-management programme. Stroke 2011;42(6):1673-9. [DOI: 10.1161/ STROKEAHA.110.601997]

Duncan 2011 \{published data only\}

Duncan PW, Sullivan KJ, Behrman AL, Azen SP, Wu SS, Nadeau SE, et al.Body-weight supported treadmill rehabilitation after stroke. New England Journal of Medicine 2011;364(21):2026-36. [DOI: 10.1056/ NEJMoa1010790]

Eng 2010 \{published data only\}

Eng JJ. Fitness and mobility exercise (FAME) programme for stroke. Topics in Geriatric Rehabilitation 2010;26(4): 310-23. [DOI: 10.1097/TGR.0b013e3181fee736]

Halvarsson 2011 \{published data only\} Halvarsson A, Oddsson L, Olsson E, Farén E, Pettersson A, Ståhle A. Effects of new, individually adjusted, progressive balance group training for elderly people with fear of falling and tend to fall: a randomized controlled trial. Clinical Rehabilitation 2011;25(11):1021-31. [DOI: 10.1177/ 0269215511411937]

Hesse 2011 \{published data only\}

Hesse S, Welz A, Werner C, Quentin B, Wissel J. Comparison of an intermittent high-intensity vs continuous low-intensity physiotherapy service over 12 months in community-dwelling people with stroke: a randomised trial. Clinical Rehabilitation 2011;25(2):146-56. [DOI: 10.1177/0269215510382148]

Kong 2009 \{published data only\} Kong KH, Wee SK, Ng CY, Chua K, Chan KF, Venketasubramanian $\mathrm{N}$, et al.A double-blind, placebocontrolled, randomised phase II pilot study to investigate the potential efficacy of the traditional Chinese medicine Neuroaid (MLC601) in enhancing recovery after stroke (TIERS). Cerebrovascular Diseases 2009;28(5):514-21. [DOI: 10.1159/000247001]

Kwok 2005 \{published data only\} Kwok T, Mok F, Chien WT, Tam E. Does access to bedchair pressure sensors reduce physical restraint use in the rehabilitative care setting. Journal of Clinical Nursing 2006; 15(5):581-7.

Mayo 1994 \{published data only (unpublished sought but not used)\} Mayo NE, Gloutney L, Levy AR. A randomised trial of identification bracelets to prevent falls among patients in a rehabilitation hospital. Archives of Physical Medicine and Rehabilitation 1994;75(12):1302-8.

Rossi 1990 \{published data only\} Rossi PW, Kheyfets S, Reding MJ. Fresnel prisms improve visual perception in stroke patients with homonymous hemianopia or unilateral visual neglect. Neurology 1990;40 (10):1597-9. 


\section{Von Koch 2001 \{published data only\}}

Thorsén AM, Widén Holmqvist L, Von Koch L. Early supported discharge and continued rehabilitation at home after stroke: 5-year follow-up of resource use. Journal of Stroke and Cerebrovascular Diseases 2006;15(4):139-43. Thorsén AM, Widén Holmqvist LW, de Pedro-Cuesta J, Von Koch L. A randomised controlled trial of early supported discharge and continued rehabilitation at home after stroke: five-year follow-up of patient outcome. Stroke 2005;36(2):297-303.

* Von Koch L, de Pedro-Cuesta J, Kostulas V, Almazan J, Widén Holmqvist L. Randomized controlled trial of rehabilitation at home after stroke: one-year follow-up of patient outcome, resource use and cost. Cerebrovascular Diseases 2001;12(2):131-8.

Von Koch L, Widén Holmqvist L, Kostulas V, Almazan J, de Pedro-Cuesta J. A randomised controlled trial of rehabilitation at home after stroke in southwest Stockholm: outcome at six months. Scandinavian Journal of Rehabilitation Medicine 2000;32(2):80-6.

Widén Holmqvist L, Von Koch L, Kostulas V, Holm M, Widsell G, Tegler H, et al.A randomised controlled trial of rehabilitation at home after stroke in southwest Stockholm. Stroke 1998;29(3):591-7.

\section{References to studies awaiting assessment}

\section{Cheng 2001 \{published data only\}}

Cheng PT, Wu SH, Liam MY, Wong AM, Tang FT. Symmetrical body-weight distribution training in stroke patients and its effect on fall prevention. Archives of Physical Medicine and Rehabilitation 2001;82(12):1650-4.

Rosendahl 2008 \{published data only\}

Rosendahl E, Gustafson Y, Nordin E, Lundin-Olsson L, Nyberg L. A randomized controlled trial of fall prevention by a high-intensity functional exercise program for older people living in residential care facilities. Aging Clinical and Experimental Research 2008;20(1):67-75.

Sato 2003 \{published data only\}

Sato Y, Metoki N, Iwamoto J, Satoh K. Amelioration of osteoporosis and hypovitaminosis $\mathrm{D}$ by sunlight exposure in stroke patients. Neurology 2003;61(3):338-42.

Sato 2005b \{published data only\}

Sato Y, Iwamoto J, Kanoko T, Satoh K. Risedronate sodium therapy for prevention of hip fracture in men 65 years or older after stroke. Archives of Internal Medicine 2005;165 (15):1743-8.

Sato 2005c \{published data only\}

Sato Y, Iwamoto J, Kanoko T, Satoh K. Risedronate therapy for prevention of hip fracture after stroke in elderly women. Neurology 2005;64(5):811-6.

\section{Additional references}

\section{Ashburn 2008}

Ashburn A, Hyndman D, Pickering R, Yardley L, Harris S. Predicting people with stroke at risk of falls. Age and Ageing 2008;37(3):270-6. [DOI: 10.1093/ageing/afn066]

\section{Batchelor 2010}

Batchelor F, Hill K, Mackintosh S, Said C. What works in falls prevention after stroke? A systematic review and metaanalysis. Stroke 2010;41(1):1715-22. [DOI: 10.1161/ STROKEAHA.109.570390]

Belgen 2006

Belgen B, Beninato M, Sullivan PE, Narielwalla K. The association of balance capacity and falls self-efficacy with history of falling in community-dwelling people with chronic stroke. Archives of Physical Medicine and Rehabilitation 2006;87(4):554-61.

Burridge 2007

Burridge JH, Haugland M, Larsen B, Pickering RM, Svaneborg N, Iversen HK, et al.Phase II trial to evaluate the ActiGait implanted drop-foot stimulator in established hemiplegia. Journal of Rehabilitation Medicine 2007;39(3): 212-8.

Cameron 2012

Cameron ID, Gillespie LD, Robertson MC, Murray GR, Hill KD, Cumming RG, et al. Interventions for preventing falls in older people in care facilities and hospitals. Cochrane Database of Systematic Reviews 2012, Issue 12. [DOI: 10.1002/14651858.CD005465.pub3]

\section{Cochrane Handbook}

Higgins JPT, Green S (editors). Cochrane Handbook for Systematic Reviews of Interventions Version 5.1.0 [updated March 2011]. The Cochrane Collaboration, 2011. Available from www.cochrane-handbook.org.

\section{Davenport 1996}

Davenport RJ, Dennis MS, Wellwood I, Warlow CP. Complications after acute stroke. Stroke 1996;27(3): 415-20.

\section{Gillespie 2012}

Gillespie LD, Robertson MC, Gillespie WJ, Sherrington C, Gates S, Clemson LM, et al. Interventions for preventing falls in older people living in the community. Cochrane Database of Systematic Reviews 2012, Issue 9. [DOI: 10.1002/14651858.CD007146.pub3]

Harris 2005

Harris JE, Eng JJ, Marigold DS, Tokuno CD, Louis CL. Relationship of balance and mobility to fall incidence in people with chronic stroke. Physical Therapy 2005;85(2): $150-8$.

\section{Hauer 2006}

Hauer K, Lamb SE, Jorstad EC, Todd C, Becker C, the ProFaNE-group. Systematic review of definitions and methods of measuring falls in randomised controlled fall prevention trials. Age and Ageing 2006;35(1):5-10.

\section{Higgins 2003}

Higgins JP, Thompson SG, Deeks JJ, Altman DG. Measuring inconsistency in meta-analyses. BMJ 2003; 7414:557-60.

\section{Higgins 2011a}

Higgins JPT, Altman DG, Sterne JAC on behalf of the Cochrane Statistical Methods Group and the Cochrane 
Bias Methods Group. Chapter 8: Assessing risk of bias in included studies. In: Higgins JPT, Green S (editors). Cochrane Handbook for Systematic Reviews of Interventions Version 5.1.0 [updated March 2011]. The Cochrane Collaboration, 2011. Available from www.cochrane-handbook.org.

\section{Indredavik 2008}

Indredavik B, Rohweder G, Naalsund E, Lydersen S. Medical complications in a comprehensive stroke unit and an early supported discharge service. Stroke 2008;39(2): 414-20.

\section{Kerse 2008}

Kerse N, Parag V, Feigin VL, McNaughton H, Hackett ML, Bennett DA, et al.Falls after stroke: results from the Auckland Regional Community Stroke (ARCOS) Study, 2002 to 2003. Stroke 2008;39(6):1890-3. [DOI: 10.1161/ STROKEAHA.107.509885]

\section{Kuan 1999}

Kuan TS, Tsou JY, Su FC. Hemiplegic gait of stroke patients: the effect of using a cane. Archives of Physical Medicine and Rehabilitation 1999;80(7):777-84.

\section{Kunkel 2011}

Kunkel D, Pickering RM, Ashburn AM. Comparison of retrospective interviews and prospective diaries to facilitate fall reports among people with stroke. Age and Ageing 2011; 40(2):277-80. [DOI: 10.1093/ageing/afq177]

\section{Lamb 2005}

Lamb SE, Jorstad-Stein EC, Hauer K, Becker C, Prevention of Falls Network Europe and Outcomes Consensus Group. Development of a common outcome data set for fall injury prevention trials: the Prevention of Falls Network Europe consensus. Journal of the American Geriatrics Society 2005; 53(9):1618-22.

\section{Lamb 2007}

Lamb SE, Hauer K, Becker C. Manual for the fall prevention classification system. www.profane.eu.org/documents/ Falls`Taxonomy.pdf (accessed 30 January 2013).

\section{Lamb 2011}

Lamb SE, Becker C, Gillespie LD, Smith JL, Finnegan $S$, Potter R, et al. Reporting of complex interventions in clinical trials: development of a taxonomy to classify and describe fall-prevention interventions. Trials 2011;12:125. [DOI: $10.1186 / 1745-6215-12-125$ ]

\section{Langhorne 2000}

Langhorne P, Stott DJ, Robertson L, MacDonald J, Jones L, McAlpine C, et al.Medical complications after stroke: a multicenter study. Stroke 2000;31(6):1223-9.

\section{Sackley 2008}

Sackley C, Brittle N, Patel S, Ellins J, Scott M, Wright C, et al.The prevalence of joint contractures, pressure sores, painful shoulder, other pain, falls, and depression in the year after a severely disabling stroke. Stroke 2008;39(12): 3329-34. [DOI: 10.1161/STROKEAHA.108.518563]

\section{Shepherd 2001}

Shepherd RB. Exercise and training to optimize functional motor performance in stroke: driving neural reorganization? . Neural Plasticity 2001;8(1-2):121-9.

\section{Stack 1999}

Stack E, Ashburn A. Fall events described by people with Parkinson's disease: implications for clinical interviewing and the research agenda. Physiotherapy Research International 1999;4(3):190-200.

\section{Weerdesteyn 2008}

Weerdesteyn V, De Niet M, Van Duijnhoven HJ, Geurts AC. Falls in individuals with stroke. Journal of Rehabilitation Research and Development 2008;45(8):1195-213.

* Indicates the major publication for the study 


\section{CHARACTERISTICS OF STUDIES}

\section{Characteristics of included studies [ordered by study ID]}

Batchelor 2012

\begin{tabular}{|c|c|c|}
\hline Methods & \multicolumn{2}{|c|}{ A single blind, multicentre RCT with 12-month follow-up } \\
\hline Participants & \multicolumn{2}{|c|}{$\begin{array}{l}\text { A total of } 156 \text { participants were recruited. Participants were people with stroke at risk of } \\
\text { recurrent falls being discharged home from rehabilitation }\end{array}$} \\
\hline Interventions & \multicolumn{2}{|c|}{$\begin{array}{l}\text { In addition to usual care after discharge (physiotherapy and occupational therapy and } \\
\text { follow-up by the general medical practitioner), the 12-month study programme consisted } \\
\text { of: } \\
\text { For the intervention group }(\mathrm{N}=71) \text { : a physiotherapist providing a multifactorial, in- } \\
\text { dividually-tailored falls prevention programme, consisting of: (1) individualised home } \\
\text { exercise programme based on the Otago Exercise Programme; (2) falls risk minimisation } \\
\text { strategies; (3) written and verbal education about falls risk factors and risk minimisation; } \\
\text { (4) injury risk minimisation strategies, and }(5) \text { a falls prevention booklet } \\
\text { For the control group }(\mathrm{N}=85) \text { : a falls prevention booklet }\end{array}$} \\
\hline Outcomes & \multicolumn{2}{|c|}{$\begin{array}{l}\text { Rate of falls, number of fallers, number of people sustaining fall-related fractures, and } \\
\text { quality of life }\end{array}$} \\
\hline \multicolumn{3}{|l|}{ Notes } \\
\hline \multicolumn{3}{|l|}{ Risk of bias } \\
\hline Bias & Authors' judgement & Support for judgement \\
\hline $\begin{array}{l}\text { Random sequence generation (selection } \\
\text { bias) }\end{array}$ & Low risk & $\begin{array}{l}\text { Quote: “... participants were allocated into } \\
\text { either the control group or the intervention } \\
\text { group ( } 1: 1 \text { allocation ration, simple ran- } \\
\text { domization) using a computer-generated } \\
\text { random allocation sequence..." (page } 2 \text { ) }\end{array}$ \\
\hline Allocation concealment (selection bias) & Low risk & $\begin{array}{l}\text { Quote: “... participants were allocated into } \\
\text { either the control group or the interven- } \\
\text { tion group (1:1 allocation ration, simple } \\
\text { randomization) using a computer-gener- } \\
\text { ated random allocation sequence concealed } \\
\text { from all researchers in opaque envelopes. } \\
\text { Staff independent of the study undertook } \\
\text { sequence and concealment." (page } 2 \text { ) }\end{array}$ \\
\hline $\begin{array}{l}\text { Blinding of outcome assessment (detection } \\
\text { bias) } \\
\text { All outcomes }\end{array}$ & High risk & $\begin{array}{l}\text { Participants recorded falls themselves } \\
\text { through the use of a falls calendar }\end{array}$ \\
\hline
\end{tabular}

All outcomes

Interventions for preventing falls in people after stroke (Review) 
Batchelor 2012 (Continued)

\begin{tabular}{l|l|l}
\hline $\begin{array}{l}\text { Incomplete outcome data (attrition bias) } \\
\text { All outcomes }\end{array}$ & Low risk & $\begin{array}{l}\text { Incomplete outcome data adequately ad- } \\
\text { dressed and unlikely to seriously alter the } \\
\text { results }\end{array}$ \\
\hline $\begin{array}{l}\text { Selective reporting (reporting bias) } \\
\text { Reliable ascertainment of falls/fallers out- } \\
\text { come }\end{array}$ & Low risk & $\begin{array}{l}\text { All of the studies' prespecified outcomes } \\
\text { have been reported in the prespecified way }\end{array}$ \\
\hline & Low & $\begin{array}{l}\text { Participants returned the falls calendar each } \\
\text { month. A researcher blinded to group al- } \\
\text { location telephoned participants who did } \\
\text { not return their calendar within } 2 \text { weeks of } \\
\text { the due date }\end{array}$ \\
\hline
\end{tabular}

Dean 2010

\begin{tabular}{|c|c|c|}
\hline Methods & \multicolumn{2}{|c|}{ An assessor-blinded RCT } \\
\hline Participants & \multicolumn{2}{|c|}{$\begin{array}{l}\text { A total of } 126 \text { participants unable to walk within } 4 \text { weeks of a stroke who were undergoing } \\
\text { inpatient rehabilitation }\end{array}$} \\
\hline Interventions & \multicolumn{2}{|c|}{$\begin{array}{l}\text { A conventional stroke rehabilitation programme was provided plus } 30 \text { minutes ( } 5 \text { days } \\
\text { a week) of: } \\
\text { For the intervention group }(\mathrm{N}=64) \text { : walking in a treadmill while supported in a harness. } \\
\text { Once they attained a speed of } 0.4 \mathrm{~m} / \mathrm{s} \text { without body-weight support, } 10 \text { minutes of the } \\
\text { session was devoted to overground walking } \\
\text { For the control group }(\mathrm{N}=62 \text { ): assisted overground walking (aids allowed). If too dis- } \\
\text { abled, therapy focused on standing, shifting weight and stepping forwards and backwards } \\
\text { Interventions were provided until participants achieved independent walking or were } \\
\text { discharged from hospital }\end{array}$} \\
\hline Outcomes & \multicolumn{2}{|c|}{ Rate of falls, number of fallers, and quality of life } \\
\hline \multicolumn{3}{|l|}{ Notes } \\
\hline \multicolumn{3}{|l|}{ Risk of bias } \\
\hline Bias & Authors' judgement & Support for judgement \\
\hline $\begin{array}{l}\text { Random sequence generation (selection } \\
\text { bias) }\end{array}$ & Low risk & $\begin{array}{l}\text { Quote: "The allocation sequence was computer-generated } \\
\text { before commencement of the study and centrally located." } \\
\text { (page 98) }\end{array}$ \\
\hline Allocation concealment (selection bias) & Low risk & $\begin{array}{l}\text { Quote: "After recruitment, the central office was contacted } \\
\text { for allocation so that randomisation was secure and con- } \\
\text { cealed." (page 98) }\end{array}$ \\
\hline
\end{tabular}


Dean 2010 (Continued)

\begin{tabular}{|c|c|c|}
\hline $\begin{array}{l}\text { Blinding of outcome assessment (detection } \\
\text { bias) } \\
\text { All outcomes }\end{array}$ & High risk & $\begin{array}{l}\text { Number of falls was quantified by means of a self-reported } \\
\text { questionnaire }\end{array}$ \\
\hline $\begin{array}{l}\text { Incomplete outcome data (attrition bias) } \\
\text { All outcomes }\end{array}$ & Low risk & $\begin{array}{l}\text { Incomplete outcome data adequately addressed and unlikely } \\
\text { to seriously alter the results }\end{array}$ \\
\hline Selective reporting (reporting bias) & Low risk & $\begin{array}{l}\text { All of the studies' prespecified outcomes have been reported } \\
\text { in the prespecified way }\end{array}$ \\
\hline $\begin{array}{l}\text { Reliable ascertainment of falls/fallers out- } \\
\text { come }\end{array}$ & High risk & $\begin{array}{l}\text { Fall ascertainment method used was retrospective recall (6- } \\
\text { month period) }\end{array}$ \\
\hline
\end{tabular}

Dean 2012

\begin{tabular}{|c|c|}
\hline Methods & An assessor-blinded RCT \\
\hline Participants & A total of 151 community-dwelling people after stroke \\
\hline Interventions & $\begin{array}{l}\text { Both groups participated in exercise classes of } 45 \text { to } 60 \text { minutes delivered by a physio- } \\
\text { therapist weekly for } 40 \text { weeks over a } 1 \text {-year period consisting of: } \\
\text { For the intervention group }(\mathrm{N}=76) \text { : an exercise intervention designed to enhance mo- } \\
\text { bility, prevent falls, and increase physical activity - the WEBB programme involving task- } \\
\text { related training with progressive balance and strengthening exercises as well as walking } \\
\text { and stair climbing. The intervention was delivered in a weekly circuit-style group exercise } \\
\text { class and a home exercise programme (to be completed at least } 3 \text { times per week), and } \\
\text { advice to increase walking was given } \\
\text { For the control group }(\mathrm{N}=75) \text { : the exercise class was designed to improve upper limb } \\
\text { function, manage upper limb contracture with task-related strength and co-ordination } \\
\text { training, and improve cognition with matching, sorting and sequencing tasks. The con- } \\
\text { trol group was also prescribed a home programme (to be completed at least } 3 \text { times per } \\
\text { week) }\end{array}$ \\
\hline Outcomes & Rate of falls, number of fallers, quality of life, and adverse events \\
\hline Notes & \\
\hline
\end{tabular}

\section{Risk of bias}

\begin{tabular}{lll}
\hline Bias & Authors' judgement & Support for judgement \\
\hline $\begin{array}{l}\text { Random sequence generation (selection } \\
\text { bias) }\end{array}$ & Low risk & $\begin{array}{l}\text { Quote: “The allocation sequence was computer generated } \\
\text { before commencement of the study ...” (page 2) }\end{array}$ \\
\hline Allocation concealment (selection bias) & Low risk & $\begin{array}{l}\text { Quote: “... and a set of consecutively numbered, sealed } \\
\text { opaque envelopes containing the allocation was centrally } \\
\text { generated for each stroke club.” (page 2) }\end{array}$
\end{tabular}

Interventions for preventing falls in people after stroke (Review) 
Dean 2012 (Continued)

\begin{tabular}{|c|c|c|}
\hline $\begin{array}{l}\text { Blinding of outcome assessment (detection } \\
\text { bias) } \\
\text { All outcomes }\end{array}$ & High risk & $\begin{array}{l}\text { Participants recorded falls themselves through the use of a } \\
\text { falls calendar }\end{array}$ \\
\hline $\begin{array}{l}\text { Incomplete outcome data (attrition bias) } \\
\text { All outcomes }\end{array}$ & Low risk & $\begin{array}{l}\text { Incomplete outcome data adequately addressed and unlikely } \\
\text { to seriously alter the results }\end{array}$ \\
\hline Selective reporting (reporting bias) & Low risk & $\begin{array}{l}\text { All of the studies' prespecified outcomes have been reported } \\
\text { in the prespecified way }\end{array}$ \\
\hline $\begin{array}{l}\text { Reliable ascertainment of falls/fallers out- } \\
\text { come }\end{array}$ & Low risk & $\begin{array}{l}\text { Participants returned the falls calendar each month. A re- } \\
\text { searcher telephoned participants who did not return their } \\
\text { calendar }\end{array}$ \\
\hline
\end{tabular}

\section{Green 2002}

\begin{tabular}{l|l}
\hline Methods & A single-masked RCT \\
\hline Participants & $\begin{array}{l}\text { A total of } 170 \text { patients with mobility problems more than } 1 \text { year after stroke were included } \\
\text { in the study }\end{array}$ \\
\hline Interventions & $\begin{array}{l}\text { Intervention group }(\mathrm{N}=85): \text { physiotherapy treatment by an established community } \\
\text { physiotherapy service as part of their usual work. Patients treated with a problem-solving } \\
\text { approach at home or in outpatient centre. A standard maximum contact period of } 13 \\
\text { weeks with a minimum of } 3 \text { contacts per patient was agreed } \\
\text { Control group }(\mathrm{N}=85): \text { no intervention. }\end{array}$ \\
\hline Outcomes & Number of fallers and quality of life \\
\hline Notes & \\
\hline
\end{tabular}

Risk of bias

\begin{tabular}{lll}
\hline Bias & Authors' judgement & Support for judgement \\
\hline $\begin{array}{l}\text { Random sequence generation (selection } \\
\text { bias) }\end{array}$ & Low risk & $\begin{array}{l}\text { Quote: "Randomisation was achieved by numbered, sealed, } \\
\text { opaque envelopes prepared from random number tables ..." } \\
\text { (page 200) }\end{array}$ \\
\hline $\begin{array}{l}\text { Allocation concealment (selection bias) } \\
\text { Blinding of outcome assessment (detection }\end{array}$ & Low risk & High risk \\
$\begin{array}{l}\text { bias) } \\
\text { All outcomes }\end{array}$ & $\begin{array}{l}\text { Quote: "Randomisation was achieved by numbered, sealed, } \\
\text { opaque envelopes prepared from random number tables ..." } \\
\text { (page 200) }\end{array}$ \\
\hline \begin{tabular}{l} 
Participants were asked to recall falls themselves \\
\hline
\end{tabular} & & \\
\hline
\end{tabular}


Green 2002 (Continued)

\begin{tabular}{l|l|l}
\hline $\begin{array}{l}\text { Incomplete outcome data (attrition bias) } \\
\text { All outcomes }\end{array}$ & Low risk & $\begin{array}{l}\text { Incomplete outcome data adequately addressed and unlikely to } \\
\text { seriously alter the results }\end{array}$ \\
\hline $\begin{array}{l}\text { Selective reporting (reporting bias) } \\
\text { Reliable ascertainment of falls/fallers out- } \\
\text { come }\end{array}$ & High risk & $\begin{array}{l}\text { All of the studies' prespecified outcomes have been reported in } \\
\text { the prespecified way }\end{array}$ \\
\hline
\end{tabular}

Haran 2010

\begin{tabular}{l|l}
\hline Methods & Parallel assessor-blinded RCT \\
\hline Participants & $\begin{array}{l}\text { A subgroup of } 46 \text { people with stroke }(\mathrm{N}=606 \text { for the total group) who were regular } \\
\text { wearers of multifocal glasses and had an increased risk of falls }\end{array}$ \\
\hline Interventions & $\begin{array}{l}\text { Intervention group }(\mathrm{N}=22) \text { : examination by an optometrist with prescription for a pair } \\
\text { of single lens distance glasses } \\
\text { Control group }(\mathrm{N}=24): \text { examination by an optometrist }\end{array}$ \\
\hline Outcomes & Rate of falls, number of fallers, number of fall-related fractures, and quality of life \\
\hline Notes & \\
\hline
\end{tabular}

\section{Risk of bias}

\begin{tabular}{l|l|l}
\hline Bias & Authors' judgement & Support for judgement \\
\hline $\begin{array}{l}\text { Random sequence generation (selection } \\
\text { bias) }\end{array}$ & Unclear risk & $\begin{array}{l}\text { Insufficient information provided about the sequence } \\
\text { generation process }\end{array}$ \\
\hline $\begin{array}{l}\text { Allocation concealment (selection bias) } \\
\text { Llinding of outcome assessment (detection } \\
\text { bias) }\end{array}$ & Low risk & $\begin{array}{l}\text { Quote: “... by using sequentially numbered opaque en- } \\
\text { velopes containing group assignment." (page 2) }\end{array}$ \\
\hline $\begin{array}{l}\text { Incomplete outcome data (attrition bias) } \\
\text { All outcomes }\end{array}$ & Low risk & $\begin{array}{l}\text { Participants recorded falls themselves through the use } \\
\text { of a falls calendar }\end{array}$ \\
\hline $\begin{array}{l}\text { Selective reporting (reporting bias) } \\
\text { Reliable ascertainment of falls/fallers out- } \\
\text { come }\end{array}$ & Low risk & $\begin{array}{l}\text { Incomplete outcome data adequately addressed and un- } \\
\text { likely to seriously alter the results }\end{array}$ \\
\hline
\end{tabular}


Holmgren 2010

\begin{tabular}{|c|c|c|}
\hline Methods & \multicolumn{2}{|c|}{ Single-centre, single-blinded RCT } \\
\hline Participants & \multicolumn{2}{|c|}{ A total of 34 people after stroke with risk of falls were included in the study } \\
\hline Interventions & \multicolumn{2}{|c|}{$\begin{array}{l}\text { A five-week programme consisting of: } \\
\text { For the intervention group }(\mathrm{N}=15) \text { : the high-intensity functional exercises (HIFE) } \\
\text { programme consisting of (1) individualised exercise sessions, } 45 \text { minutes, six times a week } \\
\text { ( } 30 \text { sessions in a 5-week period) including physical activity and functional performance, } \\
\text { aimed at improving lower-limb strength, balance and gait ability; (2) implementing the } \\
\text { functional exercises into real-life situations (a second } 45 \text {-minute session); (3) a 1-hour } \\
\text { educational session ( } 1 \text { per week, so } 5 \text { in total) with discussions about the increased risk } \\
\text { of complications after stroke, such as falls. During the last week of intervention, an } \\
\text { individualised home-based exercises programme was designed for each participant. The } \\
\text { instruction was to perform this programme } 3 \text { times a week at least until the 3-month } \\
\text { follow-up } \\
\text { For the control group ( } \mathrm{N}=19 \text { ): they met once a week for } 1 \text { hour of educational sessions (so } \\
5 \text { in total), containing group discussions about a variety of topics (e.g. fatigue, depression, } \\
\text { dysphagia, etc) but with no special focus on the risks of falls }\end{array}$} \\
\hline Outcomes & \multicolumn{2}{|c|}{ Number of fallers, quality of life, and adverse events } \\
\hline \multicolumn{3}{|l|}{ Notes } \\
\hline \multicolumn{3}{|l|}{ Risk of bias } \\
\hline Bias & Authors' judgement & Support for judgement \\
\hline $\begin{array}{l}\text { Random sequence generation (selection } \\
\text { bias) }\end{array}$ & Low risk & $\begin{array}{l}\text { Quote: "Randomization of subjects ... was con- } \\
\text { ducted a minimization software programme ..." } \\
\text { (page 117) }\end{array}$ \\
\hline Allocation concealment (selection bias) & Unclear risk & Method of concealment not described \\
\hline $\begin{array}{l}\text { Blinding of outcome assessment (detection } \\
\text { bias) } \\
\text { All outcomes }\end{array}$ & High risk & $\begin{array}{l}\text { Participants recorded falls themselves through the } \\
\text { use of a falls calendar }\end{array}$ \\
\hline $\begin{array}{l}\text { Incomplete outcome data (attrition bias) } \\
\text { All outcomes }\end{array}$ & Low risk & $\begin{array}{l}\text { Incomplete outcome data adequately addressed } \\
\text { and unlikely to seriously alter the results }\end{array}$ \\
\hline Selective reporting (reporting bias) & High risk & $\begin{array}{l}\text { Falls are specified for the total group, but not for } \\
\text { the intervention and control group separately }\end{array}$ \\
\hline $\begin{array}{l}\text { Reliable ascertainment of falls/fallers out- } \\
\text { come }\end{array}$ & Unclear risk & $\begin{array}{l}\text { Unclear whether the falls calendar that was used } \\
\text { throughout the 6-month follow-up had to be re- } \\
\text { turned monthly, 3-monthly or at the end of the 6- } \\
\text { month follow-up }\end{array}$ \\
\hline
\end{tabular}

Interventions for preventing falls in people after stroke (Review) 
Lau 2012

\begin{tabular}{|c|c|}
\hline Methods & RCT \\
\hline Participants & A total of 82 people in the chronic phase after stroke participated in the study \\
\hline Interventions & $\begin{array}{l}\text { An } 8 \text {-week training programme consisting of: } \\
\text { For the intervention group }(\mathrm{N}=41): 3 \text { weekly whole-body vibration (WBV) training } \\
\text { sessions. Each session consisted of a } 15 \text {-minute warm-up in sitting position and } 9 \text { to } \\
15 \text { minutes of WBV training. The WBV training comprised dynamic exercises (weight- } \\
\text { shifting, squats, single leg squats, forward lunge). The training volume and intensity } \\
\text { were systematically increased } \\
\text { For the control group ( } \mathrm{N}=41) \text { : they performed the same exercises as the intervention } \\
\text { group while standing on the same platform but with no vibration }\end{array}$ \\
\hline Outcomes & $\begin{array}{l}\text { Rate of falls, number of fallers, number of people sustaining fall-related fractures, number } \\
\text { of people with fall-related hospital admissions, and adverse events }\end{array}$ \\
\hline
\end{tabular}

\section{Risk of bias}

\begin{tabular}{l|l|l}
\hline Bias & Authors' judgement & Support for judgement \\
\hline $\begin{array}{l}\text { Random sequence generation (selection } \\
\text { bias) }\end{array}$ & Unclear risk & Method of randomisation not described \\
\hline $\begin{array}{l}\text { Allocation concealment (selection bias) } \\
\text { Low risk }\end{array}$ & $\begin{array}{l}\text { Quote: “... using sealed opaque envelopes. To ensure concealed } \\
\text { allocation, the procedures were performed by an ”off-site“ } \\
\text { searcher who was not involved in other parts of the study." (page } \\
1410)\end{array}$ \\
\hline $\begin{array}{l}\text { Blinding of outcome assessment (detection } \\
\text { bias) } \\
\text { All outcomes }\end{array}$ & High risk & $\begin{array}{l}\text { Participants recorded falls themselves through the use of a log- } \\
\text { book }\end{array}$ \\
\hline $\begin{array}{l}\text { Incomplete outcome data (attrition bias) } \\
\text { All outcomes }\end{array}$ & Low risk & $\begin{array}{l}\text { Incomplete outcome data adequately addressed and unlikely to } \\
\text { seriously alter the results }\end{array}$ \\
\hline $\begin{array}{l}\text { Selective reporting (reporting bias) } \\
\text { Reliable ascertainment of falls/fallers out- } \\
\text { come }\end{array}$ & Low risk & $\begin{array}{l}\text { All of the studies' prespecified outcomes have been reported in } \\
\text { the prespecified way }\end{array}$ \\
\hline & $\begin{array}{l}\text { Falls data were collected by means of a monthly interview until } \\
\text { six months after the end of training }\end{array}$ \\
\hline
\end{tabular}


Marigold 2005

\begin{tabular}{|c|c|c|}
\hline Methods & \multicolumn{2}{|l|}{ RCT } \\
\hline Participants & \multicolumn{2}{|c|}{ A total of 61 community-dwelling older adults with chronic stroke } \\
\hline Interventions & \multicolumn{2}{|c|}{$\begin{array}{l}\text { A } 10 \text {-week exercise programme ( } 1 \text {-hour sessions, } 3 \text { times a week) consisting of: } \\
\text { For the intervention (agility) group }(\mathrm{N}=30) \text { : } 5 \text {-minute warm-up and 5-minute cool- } \\
\text { down with a programme challenging dynamic balance and emphasising agility and mul- } \\
\text { tisensory approach inbetween. Tasks included standing in various postures, walking with } \\
\text { various challenges, sit-to-stand movement, rapid knee raise in standing and standing } \\
\text { perturbations. Eyes closed conditions and foam surfaces were incorporated for many of } \\
\text { the tasks. The tasks progressively increased in difficulty } \\
\text { For the control (stretching/weight-shifting) group ( } \mathrm{N}=31 \text { ): } 5 \text {-minute warm-up and 5- } \\
\text { minute cool-down with a programme focusing on slow, low-impact movements consist- } \\
\text { ing of stretching and weight shifting inbetween }\end{array}$} \\
\hline Outcomes & \multicolumn{2}{|c|}{$\begin{array}{l}\text { Rate of falls, number of fallers, number of people sustaining fall-related fractures, and } \\
\text { quality of life }\end{array}$} \\
\hline \multicolumn{3}{|l|}{ Notes } \\
\hline \multicolumn{3}{|l|}{ Risk of bias } \\
\hline Bias & Authors' judgement & Support for judgement \\
\hline $\begin{array}{l}\text { Random sequence generation (selection } \\
\text { bias) }\end{array}$ & Low risk & $\begin{array}{l}\text { Quote: "Participants were ... randomly assigned alphanumeric } \\
\text { codes through a random number generator." (page 417) }\end{array}$ \\
\hline Allocation concealment (selection bias) & Low risk & $\begin{array}{l}\text { Quote: " Subsequently, a person independent of the study (i.e. } \\
\text { concealed allocation) randomly assigned participants ..." (page } \\
417)\end{array}$ \\
\hline $\begin{array}{l}\text { Blinding of outcome assessment (detection } \\
\text { bias) } \\
\text { All outcomes }\end{array}$ & High risk & $\begin{array}{l}\text { Participants recorded falls themselves through the use of a falls } \\
\text { calendar }\end{array}$ \\
\hline $\begin{array}{l}\text { Incomplete outcome data (attrition bias) } \\
\text { All outcomes }\end{array}$ & Low risk & $\begin{array}{l}\text { Incomplete outcome data adequately addressed and unlikely to } \\
\text { seriously alter the results }\end{array}$ \\
\hline Selective reporting (reporting bias) & High risk & $\begin{array}{l}\text { A post hoc primary outcome analysis using a subset of data was } \\
\text { performed that was not prespecified }\end{array}$ \\
\hline $\begin{array}{l}\text { Reliable ascertainment of falls/fallers out- } \\
\text { come }\end{array}$ & Low risk & $\begin{array}{l}\text { Participants returned the falls calendar each month for a period } \\
\text { of } 1 \text { year. Follow-up telephone calls were made if the monthly } \\
\text { diary was not returned }\end{array}$ \\
\hline
\end{tabular}

Interventions for preventing falls in people after stroke (Review) 
Sato 2005a

\begin{tabular}{ll}
\hline Methods & RCT \\
\hline Participants & A total of 96 hospitalised women in the chronic phase after stroke \\
\hline Interventions & $\begin{array}{l}\text { A 2-year study with: } \\
\text { For the intervention group }(\mathrm{N}=48): 1000 \text { IU ergocalciferol (vitamin D) daily with } \\
\text { breakfast and dinner } \\
\text { For the control group }(\mathrm{N}=48) \text { : placebo with breakfast and dinner }\end{array}$ \\
\hline Outcomes & Rate of falls, number of fallers, and number of people sustaining fall-related fractures \\
\hline Notes & \\
\hline
\end{tabular}

\section{Risk of bias}

\begin{tabular}{|c|c|c|}
\hline Bias & Authors' judgement & Support for judgement \\
\hline $\begin{array}{l}\text { Random sequence generation (selection } \\
\text { bias) }\end{array}$ & Low risk & $\begin{array}{l}\text { Quote: "The patients were assigned to one of the two study } \\
\text { groups by means of computer-generated random numbering." } \\
\text { (page 188) }\end{array}$ \\
\hline Allocation concealment (selection bias) & Unclear risk & Method of concealment not described \\
\hline $\begin{array}{l}\text { Blinding of outcome assessment (detection } \\
\text { bias) } \\
\text { All outcomes }\end{array}$ & Unclear risk & $\begin{array}{l}\text { Quote: "Falls were recorded by the nurses who were instructed } \\
\text { to complete the fall protocol ..." and "... nurses ... were blinded } \\
\text { to the treatment assignment throughout the study." (page 188) } \\
\text { but nurses recording falls would also be dispensing medication }\end{array}$ \\
\hline $\begin{array}{l}\text { Incomplete outcome data (attrition bias) } \\
\text { All outcomes }\end{array}$ & High risk & $\begin{array}{l}\text { As-treated analysis with numbers of analysis lower compared to } \\
\text { baseline without CONSORT flow chart provided }\end{array}$ \\
\hline Selective reporting (reporting bias) & Low risk & $\begin{array}{l}\text { All of the studies' prespecified outcomes have been reported in } \\
\text { the prespecified way }\end{array}$ \\
\hline $\begin{array}{l}\text { Reliable ascertainment of falls/fallers out- } \\
\text { come }\end{array}$ & Low risk & Registration by nursing staff by means of fall protocol \\
\hline
\end{tabular}

Sato 2011

\begin{tabular}{ll}
\hline Methods & Open-label trial \\
\hline Participants & A total of 82 hospitalised people in the chronic phase after stroke \\
\hline Interventions & $\begin{array}{l}\text { A } 1 \text {-year study with: } \\
\text { For the intervention group }(\mathrm{N}=41): \text { a weekly } 35 \mathrm{mg} \text { dose of alendronate } \\
\text { For the control group }(\mathrm{N}=41): \text { a daily } 1 \mu \mathrm{g} \text { dose of alphacalcidol }\end{array}$ \\
\hline Outcomes & Rate of falls, number of fallers, and number of people sustaining fall-related fractures
\end{tabular}


Sato 2011 (Continued)

\begin{tabular}{|c|c|c|}
\hline \multicolumn{3}{|l|}{ Risk of bias } \\
\hline Bias & Authors' judgement & Support for judgement \\
\hline $\begin{array}{l}\text { Random sequence generation (selection } \\
\text { bias) }\end{array}$ & Low risk & $\begin{array}{l}\text { Quote: "The patients were assigned to } 1 \text { of the } 2 \text { study groups by } \\
\text { means of computer-generated random numbering." (page } 42 \text { ) }\end{array}$ \\
\hline Allocation concealment (selection bias) & Unclear risk & Method of concealment not described \\
\hline $\begin{array}{l}\text { Blinding of outcome assessment (detection } \\
\text { bias) } \\
\text { All outcomes }\end{array}$ & Unclear risk & $\begin{array}{l}\text { Quote: "Falls were recorded by nurses blinded to the subjects' } \\
\text { information ..." (page } 42 \text { ) but nurses recording falls would also } \\
\text { be dispensing medication }\end{array}$ \\
\hline $\begin{array}{l}\text { Incomplete outcome data (attrition bias) } \\
\text { All outcomes }\end{array}$ & High risk & $\begin{array}{l}\text { As-treated analysis with numbers of analysis lower compared } \\
\text { with baseline without CONSORT flow chart provided }\end{array}$ \\
\hline Selective reporting (reporting bias) & Low risk & $\begin{array}{l}\text { All of the studies' prespecified outcomes have been reported in } \\
\text { the prespecified way }\end{array}$ \\
\hline $\begin{array}{l}\text { Reliable ascertainment of falls/fallers out- } \\
\text { come }\end{array}$ & Low risk & Registration by nursing staff by means of fall registration \\
\hline
\end{tabular}

$\mathrm{m} / \mathrm{s}$ : metres per second

RCT: randomised controlled trial

\section{Characteristics of excluded studies [ordered by study ID]}

\begin{tabular}{ll}
\hline Study & Reason for exclusion \\
\hline Barreca 2004 & No true randomisation of participants \\
\hline Bernhardt 2008 & Falls outcome included as adverse event \\
\hline Boysen 2009 & Falls outcome included as adverse event \\
\hline Cadilhac 2011 & Falls outcome included as adverse event \\
\hline Duncan 2011 & Falls outcome included as adverse event \\
\hline Eng 2010 & Narrative review, not including any new results \\
\hline $\begin{array}{l}\text { Halvarsson 2011 } \\
\text { Only } 4 \text { people with stroke included in the study (3 in the intervention and 1 in the control group) }\end{array}$ \\
\hline $\begin{array}{l}\text { Interventions for preventing falls in people after stroke (Review) } \\
\text { Copyright @ 2013 The Cochrane Collaboration. Published by John Wiley \& Sons, Ltd. }\end{array}$
\end{tabular}


(Continued)

\begin{tabular}{ll}
\hline Hesse 2011 & Falls outcome included as adverse event \\
\hline Kong 2009 & Falls outcome included as adverse event \\
\hline Kwok 2005 & Falls outcome included as adverse event \\
\hline Mayo 1994 & First author unable to provide details and data for stroke subgroup \\
\hline Rossi 1990 & Falls outcome included as adverse event \\
\hline Von Koch 2001 & Falls outcome included as adverse event \\
\hline
\end{tabular}

\section{Characteristics of studies awaiting assessment [ordered by study ID]}

\section{Cheng 2001}

\begin{tabular}{ll}
\hline Methods & A prospective study where patients were randomly divided into intervention and control groups \\
\hline Participants & $\begin{array}{l}54 \text { patients with hemiplegic stroke (30 in the intervention group, } 24 \text { in the control group) admitted to hospital- } \\
\text { based rehabilitation units }\end{array}$ \\
\hline Interventions & $\begin{array}{l}\text { Participants in the control group received conventional stroke rehabilitation } \\
\text { Participants in the intervention group received conventional stroke rehabilitation plus standing postural symmetry } \\
\text { training (through use of a standing biofeedback trainer) and repetitive sit-to-stand training, for } 50 \text { minutes, } 5 \text { days a } \\
\text { week for } 3 \text { weeks }\end{array}$ \\
\hline Outcomes & Number of fallers \\
\hline Notes & Randomisation unclear. Author contacted to provide necessary details but no response \\
\hline
\end{tabular}

Rosendahl 2008

\begin{tabular}{ll}
\hline Methods & RCT with 6-month follow-up period \\
\hline Participants & A total of 191 older people who were dependent in activities of daily living and living in residential care facilities \\
\hline Interventions & $\begin{array}{l}\text { Participants were randomly allocated to an intervention group receiving high-intensity functional exercise programme } \\
\text { or a control group, each receiving } 29 \text { sessions over a 3-month period }\end{array}$ \\
\hline Outcomes & Rate of falls and number of fallers \\
\hline Notes & This potentially includable study was identified via contact with an expert \\
\hline
\end{tabular}


Sato 2003

\begin{tabular}{ll}
\hline Methods & A 12-month randomised and prospective study \\
\hline Participants & A chronic stroke sample of 129 in the intervention group and 129 in the control group \\
\hline Interventions & $\begin{array}{l}\text { Participants in the intervention group received regular sunlight exposure for } 12 \text { months } \\
\text { Participants in the control group (sunlight-deprived) did not receive sunlight exposure }\end{array}$ \\
\hline Outcomes & Number of falls and fracture incidence \\
\hline Notes & $\begin{array}{l}\text { Unclear if primary or secondary aim of intervention was to prevent falls. Author contacted to provide necessary details } \\
\text { but no response }\end{array}$ \\
\hline
\end{tabular}

\section{Sato 2005b}

\begin{tabular}{|c|c|}
\hline Methods & An 18-month randomised double-blind trial \\
\hline Participants & A total of 280 males in the subacute stage after stroke: 140 in the intervention group and 140 in the control group \\
\hline Interventions & $\begin{array}{l}\text { Participants in the intervention group received a daily dose of } 2.5 \mathrm{mg} \text { risedronate sodium } \\
\text { Participants in the control group received placebo }\end{array}$ \\
\hline Outcomes & Number of falls and number of fallers; hip fracture incidence \\
\hline Notes & $\begin{array}{l}\text { Unclear if primary or secondary aim of intervention was to prevent falls. Author contacted to provide necessary details } \\
\text { but no response }\end{array}$ \\
\hline
\end{tabular}

\section{Sato 2005c}

\begin{tabular}{|c|c|}
\hline Methods & A 12-month, randomised, double-blind, placebo-controlled trial \\
\hline Participants & An acute stroke sample of 187 in the intervention group and 187 in the control group \\
\hline Interventions & $\begin{array}{l}\text { Participants in the intervention group received a daily dose of } 2.5 \mathrm{mg} \text { risedronate for } 12 \text { months } \\
\text { Participants in the control group received placebo }\end{array}$ \\
\hline Outcomes & Number of falls and number of fallers, hip fracture incidence \\
\hline Notes & $\begin{array}{l}\text { Unclear if primary or secondary aim of intervention was to prevent falls. Author contacted to provide necessary details } \\
\text { but no response }\end{array}$ \\
\hline
\end{tabular}


DATA ANDANALYSES

\section{Comparison 1. Exercise}

\begin{tabular}{lccll} 
Outcome or subgroup title & $\begin{array}{c}\text { No. of } \\
\text { studies }\end{array}$ & $\begin{array}{c}\text { No. of } \\
\text { participants }\end{array}$ & \multicolumn{1}{c}{ Statistical method } & Effect size \\
\hline 1 Rate of falls & 5 & & Rate Ratio (Random, 95\% CI) & Subtotals only \\
1.1 Acute/subacute stage & 1 & 95 & Rate Ratio (Random, 95\% CI) & $0.92[0.45,1.90]$ \\
1.2 Chronic stage & 4 & 412 & Rate Ratio (Random, 95\% CI) & $0.75[0.41,1.38]$ \\
2 Number of fallers & 7 & & Risk Ratio (IV, Random, 95\% CI) & Subtotals only \\
2.1 Acute/subacute stage & 1 & 95 & Risk Ratio (IV, Random, 95\% CI) & $1.19[0.83,1.71]$ \\
2.2 Chronic stage & 6 & 616 & Risk Ratio (IV, Random, 95\% CI) & $1.02[0.83,1.24]$ \\
\hline
\end{tabular}

Comparison 2. Environment: single lens distance glasses versus usual (multifocal) glasses

\begin{tabular}{lccll} 
Outcome or subgroup title & $\begin{array}{c}\text { No. of } \\
\text { studies }\end{array}$ & $\begin{array}{c}\text { No. of } \\
\text { participants }\end{array}$ & Statistical method & Effect size \\
\hline 1 Rate of falls & 1 & 43 & Rate Ratio (Random, 95\% CI) & $1.08[0.52,2.25]$ \\
2 Number of fallers & 1 & 43 & Risk Ratio (IV, Random, 95\% CI) & $0.74[0.47,1.18]$ \\
\hline
\end{tabular}




\section{Analysis I.I. Comparison I Exercise, Outcome I Rate of falls.}

Review: Interventions for preventing falls in people after stroke

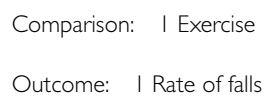

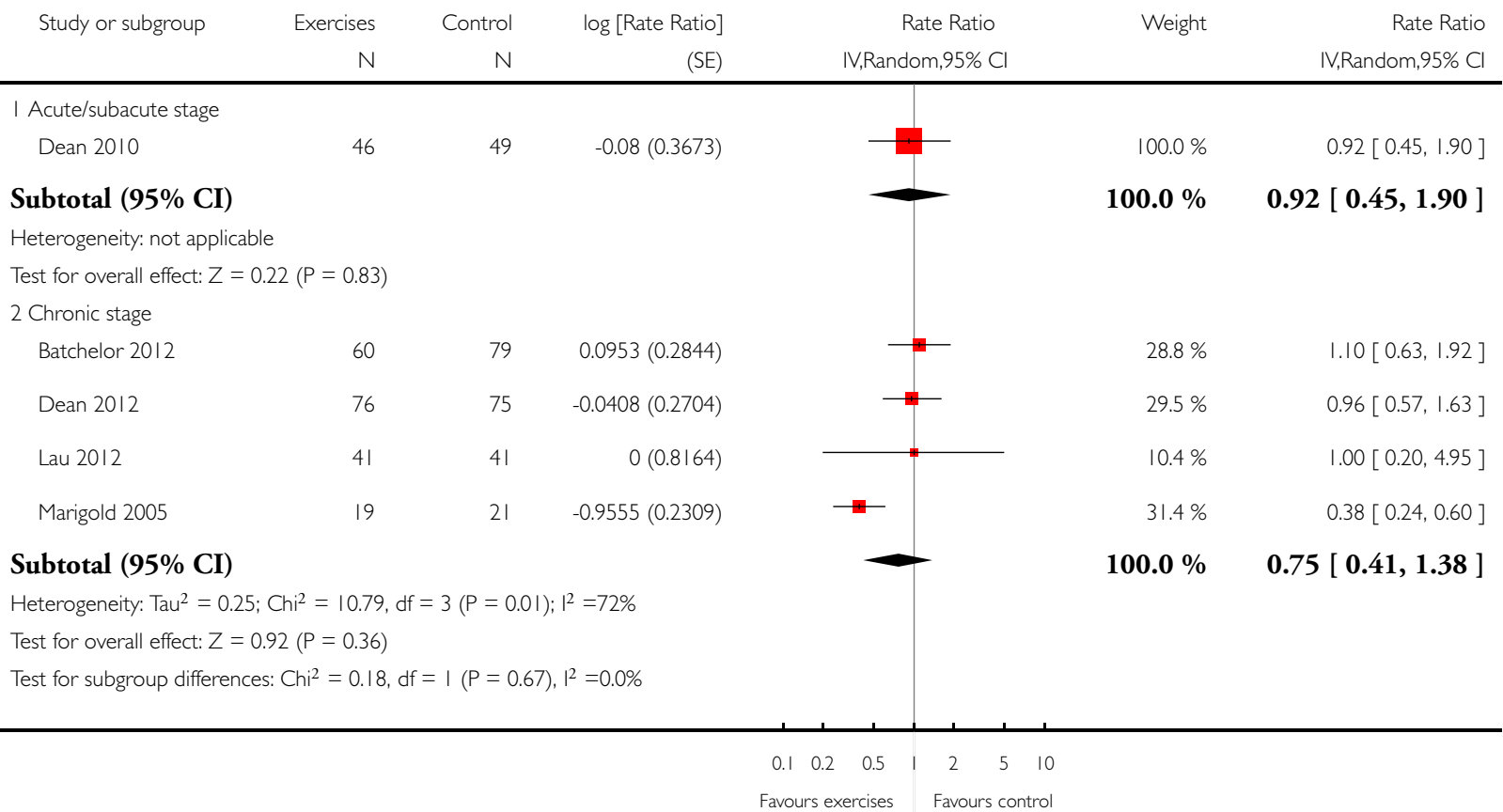




\section{Analysis I.2. Comparison I Exercise, Outcome 2 Number of fallers.}

Review: Interventions for preventing falls in people after stroke

Comparison: I Exercise

Outcome: 2 Number of fallers

Study or subgroup $\quad$ Exercises $\quad$ Control Risk Ratio Reight Ratio

$n / N \quad n / N \quad$ IV,Random,95\% Cl

IV,Random,95\% Cl

I Acute/subacute stage
Dean 2010

Subtotal $(95 \% \mathrm{CI})$

$28 / 46 \quad 25 / 49$

46

49

$100.0 \%$

I.19[0.83, ..71 ]

Total events: 28 (Exercises), 25 (Control)

Heterogeneity: not applicable

Test for overall effect: $Z=0.96(P=0.34)$

2 Chronic stage

Batchelor 2012

$29 / 60$

Dean 2012

$47 / 76$

$46 / 79$

Green 2002

$30 / 85$

$38 / 75$

Holmgren 2010

$5 / 15$

$23 / 85$

Lau 2012

$3 / 41$

$6 / 19$

$11 / 19$

$3 / 41$

Marigold 2005

296

$16 / 21$

320

$00.0 \%$

$1.19[0.83,1.71]$

Subtotal (95\% CI)

$28.2 \%$

$33.6 \%$

$16.3 \%$

$4.0 \%$

$1.6 \%$

$16.3 \%$

$100.0 \%$

$$
\begin{aligned}
& 0.83[0.60,1.14] \\
& 1.22[0.92,1.62] \\
& 1.30[0.83,2.05] \\
& 1.06[0.40,2.80] \\
& 1.00[0.21,4.67] \\
& 0.76[0.48,1.19]
\end{aligned}
$$

$1.02[0.83,1.24]$

Total events: 125 (Exercises), 132 (Control)

Heterogeneity: $\operatorname{Tau}^{2}=0.01 ; \mathrm{Chi}^{2}=5.88, \mathrm{df}=5(\mathrm{P}=0.32) ; \mathrm{I}^{2}=15 \%$

Test for overall effect: $Z=0.15(P=0.88)$

Test for subgroup differences: $\mathrm{Chi}^{2}=0.60, \mathrm{df}=\mathrm{I}(\mathrm{P}=0.44), \mathrm{I}^{2}=0.0 \%$

$\begin{array}{lllllll}0.1 & 0.2 & 0.5 & 1 & 2 & 5 & 10\end{array}$

Favours exercises Favours control 
Analysis 2.I. Comparison 2 Environment: single lens distance glasses versus usual (multifocal) glasses, Outcome I Rate of falls.

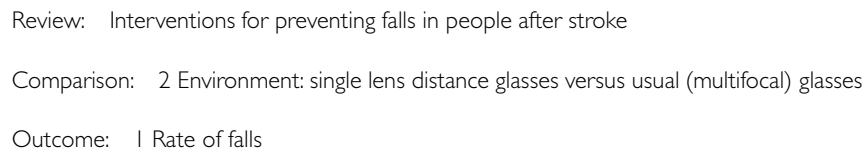

\begin{tabular}{|c|c|c|c|c|c|c|}
\hline \multirow[t]{2}{*}{ Study or subgroup } & Single lens glasses & Usual glasses & log [Rate Ratio] & Rate Ratio & Weight & Rate Ratio \\
\hline & $N$ & $N$ & (SE) & IV,Random,95\% Cl & & IV,Random,95\% Cl \\
\hline Haran 2010 & 20 & 23 & $0.0758(0.3759)$ & - & $100.0 \%$ & $1.08[0.52,2.25]$ \\
\hline
\end{tabular}

Total (95\% CI)

Heterogeneity: not applicable

Test for overall effect: $Z=0.20(P=0.84)$

Test for subgroup differences: Not applicable

$100.0 \% \quad 1.08[0.52,2.25]$

Analysis 2.2. Comparison 2 Environment: single lens distance glasses versus usual (multifocal) glasses, Outcome 2 Number of fallers.

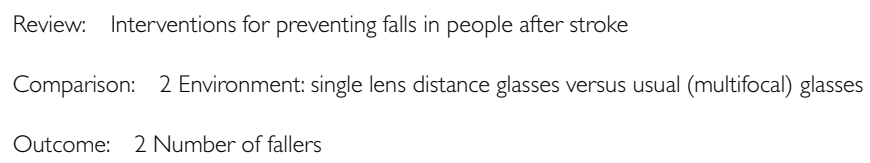

\begin{tabular}{|c|c|c|c|c|c|c|}
\hline \multirow[t]{2}{*}{ Study or subgroup } & \multirow{2}{*}{$\begin{array}{r}\text { Single lens glasses } \\
n / N\end{array}$} & \multirow{2}{*}{$\begin{array}{r}\text { Usual glasses } \\
n / N\end{array}$} & \multicolumn{2}{|r|}{ Risk Ratio } & \multirow[t]{2}{*}{ Weight } & \multirow{2}{*}{$\begin{array}{r}\text { Risk Ratio } \\
\text { IV,Random,95\% Cl }\end{array}$} \\
\hline & & & & IV,Random,95\% Cl & & \\
\hline Haran 2010 & $11 / 20$ & $17 / 23$ & & & $100.0 \%$ & $0.74[0.47,1.18]$ \\
\hline Total $(95 \%$ CI $)$ & 20 & 23 & & & $100.0 \%$ & $0.74[0.47,1.18]$ \\
\hline \multicolumn{7}{|c|}{ Total events: II (Single lens glasses), I7 (Usual glasses) } \\
\hline \multicolumn{7}{|c|}{ Heterogeneity: not applicable } \\
\hline \multicolumn{7}{|c|}{ Test for overall effect: $Z=1.25(P=0.21)$} \\
\hline \multicolumn{7}{|c|}{ Test for subgroup differences: Not applicable } \\
\hline
\end{tabular}




\section{A P P E N D I C E S}

\section{Appendix I. MEDLINE search strategy}

1. cerebrovascular disorders/ or exp basal ganglia cerebrovascular disease/ or exp brain ischemia/ or exp carotid artery diseases/ or exp intracranial arterial diseases/ or exp "intracranial embolism and thrombosis"/ or exp intracranial hemorrhages/ or stroke/ or exp brain infarction/ or vasospasm, intracranial/ or vertebral artery dissection/

2. (stroke or poststroke or post-stroke or cerebrovasc\$ or brain vasc\$ or cerebral vasc\$ or cva \$ or apoplex\$ or SAH).tw.

3. ((brain $\$$ or cerebr $\$$ or cerebell\$ or intracran $\$$ or intracerebral) adj5 (isch?emi $\$$ or infarct $\$$ or thrombo $\$$ or emboli $\$$ or occlus $\$)$ ).tw.

4. ((brain $\$$ or cerebr $\$$ or cerebell\$ or intracerebral or intracranial or subarachnoid) adj5 (haemorrhage $\$$ or hemorrhage $\$$ or haematoma $\$$ or hematoma $\$$ or bleed $\$)$ ).tw.

5. hemiplegia/ or exp paresis/

6. (hemipleg\$ or hemipar\$ or paresis or paretic).tw.

7. exp gait disorders, neurologicl

8. 1 or 2 or 3 or 4 or 5 or 6 or 7

9. accidental falls/ or accidents/ or exp accident prevention/ or accidents, home/ or accident proneness/

10. (fall or falls or faller or fallen or fallers or falling or fall-related or near-fall or falls-efficacy scale).tw.

11. (slip or slips or slipped or slipping or trip or trips or tripped or tripping).tw.

12. (stumble $\$$ or tumble $\$$ ).tw

13. (lose adj5 footing).tw.

14. 9 or 10 or 11 or 12 or 13

15. 8 and 14

16. Randomized Controlled Trials as Topic/

17. random allocation/

18. Controlled Clinical Trials as Topic/

19. control groups/

20. clinical trials as topic/ or clinical trials, phase i as topic/ or clinical trials, phase ii as topic/ or clinical trials, phase iii as topic/ or clinical trials, phase iv as topic/

21. double-blind method/

22. single-blind method/

23. Placebos/

24. placebo effect/

25. cross-over studies/

26. Multicenter Studies as Topic/

27. Therapies, Investigational/

28. Research Design/

29. Program Evaluation/

30. evaluation studies as topic/

31. randomised controlled trial.pt.

32. controlled clinical trial.pt.

33. (clinical trial or clinical trial phase i or clinical trial phase ii or clinical trial phase iii or clinical trial phase iv).pt.

34. multicenter study.pt.

35. (evaluation studies or comparative study).pt.

36. random\$.tw.

37. (controlled adj5 (trial\$ or stud\$)).tw.

38. (clinical\$ adj5 trial\$).tw.

39. ((control or treatment or experiment\$ or intervention) adj5 (group\$ or subject\$ or patient\$)).tw.

40. (quasi-random $\$$ or quasi random $\$$ or pseudo-random $\$$ or pseudo random $\$$ ).tw.

41. ((multicenter or multicentre or therapeutic) adj5 (trial\$ or stud\$)).tw.

42. ((control or experiment $\$$ or conservative) adj5 (treatment or therapy or procedure or manage\$)).tw.

43. ( (singl\$ or doubl\$ or tripl\$ or trebl\$) adj5 (blind $\$$ or mask $\$)$ ).tw.

44. (coin adj5 (flip or flipped or toss\$)).tw.

45. versus.tw.

Interventions for preventing falls in people after stroke (Review)

Copyright $\odot 2013$ The Cochrane Collaboration. Published by John Wiley \& Sons, Ltd. 
46. (cross-over or cross over or crossover).tw.

47. placebo\$.tw.

48. sham.tw.

49. (assign $\$$ or alternate or allocat $\$$ or counterbalance $\$$ or multiple baseline).tw.

50. controls.tw.

51. (treatment $\$$ adj6 order).tw.

52. or/16-51

53.15 and 52

54. limit 53 to humans

\section{Appendix 2. EMBASE search strategy}

1 exp cerebrovascular disease/

2 exp basal ganglion hemorrhage/

3 exp brain ischemia/

4 exp carotid artery disease/

5 exp cerebral artery disease/

6 (intracranial embolism and thrombosis).mp. [mp=title, abstract, subject headings, heading word, drug trade name, original title, device manufacturer, drug manufacturer, device trade name, keyword]

7 exp brain hemorrhage/

8 exp brain infarction/

9 exp brain vasospasm/

10 exp artery dissection/

111 or 2 or 3 or 4 or 5 or 6 or 7 or 8 or 9 or 10

12 (stroke or poststroke or post-stroke or cerebrovasc $\$$ or brain vasc $\$$ or cerebral vasc $\$$ or cva $\$$ or apoplex $\$$ or $S A H$ ).tw.

13 ((brain $\$$ or cerebr $\$$ or cerebell $\$$ or intracran $\$$ or intracerebral) adj5 (isch?emi $\$$ or infarct $\$$ or thrombo $\$$ or emboli $\$$ or occlus $\$$ )).tw.

14 (brain $\$$ or cerebr $\$$ or cerebell $\$$ or intracerebral or intracranial or subarachnoid) adj5 (haemorrhage $\$$ or hemorrhage $\$$ or haematoma $\$$ or hematoma $\$$ or bleed $\$)$ ).tw.

15 hemiplegia/

16 paresis/ Advanced

17 ((brain $\$$ or cerebr $\$$ or cerebell $\$$ or intracerebral or intracranial or subarachnoid) adj5 (haemorrhage $\$$ or hemorrhage $\$$ or haematoma $\$$ or hematoma $\$$ or bleed $\$)$ ).tw.

18 gait disorders, neurologic.mp. or neurologic disease/

1911 or 12 or 13 or 14 or 15 or 16 or 17 or 18

$20 \mathrm{accident} /$ or "accidents and accident related phenomena"/ or falling/ or home accident/ or exp accident prevention/ or exp accident proneness/

21 (fall or falls or faller or fallen or fallers or falling or fall-related or near-fall or falls-efficacy scale).tw.

22 (slip or slips or slipped or slipping or trip or trips or tripped or tripping).tw.

23 (stumble $\$$ or tumble $\$$ ).tw.

24 (lose adj5 footing).tw.

2520 or 21 or 22 or 23 or 24

2619 and 25

27 controlled clinical trial/ or randomized controlled trial/ or "controlled clinical trial (topic)"/

28 randomization/

29 control group/

30 exp clinical trial/ or "clinical trial (topic)"/ or clinical study/ or "controlled clinical trial (topic)"/ or "multicenter study (topic)"/ or "phase 1 clinical trial (topic)"/ or "phase 2 clinical trial (topic)"/ or "phase 3 clinical trial (topic)"/ or "phase 4 clinical trial (topic)"/

31 double blind procedure/

32 single blind procedure/

33 placebo/

34 palcebo effect.mp.

35 crossover procedure/

Interventions for preventing falls in people after stroke (Review)

Copyright $\odot 2013$ The Cochrane Collaboration. Published by John Wiley \& Sons, Ltd. 
36 "multicenter study (topic)"/

37 experimental therapy/

38 methodology/

39 health care quality/

40 evaluation/

41 randomized controlled trial.mp. [mp=title, abstract, subject headings, heading word, drug trade name, original title, device manufacturer, drug manufacturer, device trade name, keyword]

42 randomised controlled trial.mp. [mp=title, abstract, subject headings, heading word, drug trade name, original title, device manufacturer, drug manufacturer, device trade name, keyword]

43 controlled clinical trial.mp. [mp=title, abstract, subject headings, heading word, drug trade name, original title, device manufacturer, drug manufacturer, device trade name, keyword]

44 (clinical trial or clinical trial phase i or clinical trial phase ii or clinical trial phase iii or clinical trial phase iv).mp. [mp=title, abstract, subject headings, heading word, drug trade name, original title, device manufacturer, drug manufacturer, device trade name, keyword] Advanced Display

45 multicenter study.mp. [mp=title, abstract, subject headings, heading word, drug trade name, original title, device manufacturer, drug manufacturer, device trade name, keyword]

46 multicentre study.mp. [mp=title, abstract, subject headings, heading word, drug trade name, original title, device manufacturer, drug manufacturer, device trade name, keyword]

47 (evaluation studies or comparative study).mp. [mp=title, abstract, subject headings, heading word, drug trade name, original title, device manufacturer, drug manufacturer, device trade name, keyword]

48 random\$.tw.

49 (controlled adj5 (trial\$ or stud\$)).tw.

50 (clinical\$ adj5 trial\$).tw.

51 ((control or treatment or experiment $\$$ or intervention) adj5 (group $\$$ or subject $\$$ or patient $\$)$ ).tw.

52 (quasi-random\$ or quasi random $\$$ or pseudo-random\$ or pseudo random\$).tw.

53 ((multicenter or multicentre or therapeutic) adj5 (trial\$ or stud\$)).tw.

54 ((control or experiment $\$$ or conservative) adj5 (treatment or therapy or procedure or manage $\$)$ ).tw.

55 ((singl\$ or doubl\$ or tripl\$ or trebl\$) adj5 (blind\$ or mask\$)).tw.

56 (coin adj5 (flip or flipped or toss\$)).tw.

57 versus.tw.

58 (cross-over or cross over or crossover).tw.

59 placebo\$.tw.

60 sham.tw.

61 (assign\$ or alternate or allocat\$ or counterbalance\$ or multiple baseline).tw.

62 controls.tw.

63 (treatment $\$$ adj6 order).tw.

6427 or 28 or 29 or 30 or 31 or 32 or 33 or 34 or 35 or 36 or 37 or 38 or 39 or 40 or 41 or 42 or 43 or 44 or 45 or 46 or 47 or 48 or 49 or 50 or 51 or 52 or 53 or 54 or 55 or 56 or 57 or 58 or 59 or 60 or 61 or 62 or 63

6526 and 64

66 limit 65 to human

\section{Appendix 3. CINAHL search strategy}

S1 (MH “Cerebrovascular Disorders")

S2 (MH "Basal Ganglia Cerebrovascular Disease+")

S3 (MH "Cerebral Ischemia+")

S4 (MH "Intracranial Arterial Diseases+") OR (MH "Intracranial Embolism and Thrombosis+") OR (MH "Intracranial Hemorrhage+") OR (MH "Stroke+")

S5 (MH "Carotid Artery Diseases+")

S6 (MH "Brain Injuries+")

S7 (MH "Cerebral Vasospasm”)

S8 (MH "Vertebral Artery Dissections")

Interventions for preventing falls in people after stroke (Review)

Copyright () 2013 The Cochrane Collaboration. Published by John Wiley \& Sons, Ltd. 
S9 TX (stroke or poststroke or post-stroke or cerebrovasc* or brain vasc* or cerebral vasc* or cva* or apoplex* or SAH)

S10 TX (brain* or cerebr* or cerebell* or intracran* or intracerebral)

S11 TX (isch?emi* or infarct* or thrombo* or emboli* or occlus*)

S12 S10 AND S11

S13 TX (brain* or cerebr* or cerebell* or intracerebral or intracranial or subarachnoid)

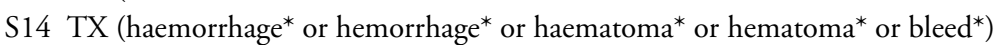

S15 S13 AND S14

S16 (MH "Hemiplegia")

S17 (MH "Paralysis+")

S18 TX (hemipleg* or hemipar* or paresis or paretic)

S19 (MH "Gait Disorders, Neurologict")

S20 S1 OR S2 OR S3 OR S4 OR S5 OR S6 OR S7 OR S8 OR S9 OR S12 OR S15 OR S16 OR S17 OR S18 OR S19

S21 (MH “Accidents, Home") OR (MH “Accidental Falls”) OR (MH “Accidents")

S22 (MH "Safety")

S23 TX (fall or falls or faller or fallen or fallers or falling or fall-related or near-fall or falls-efficacy scale)

S24 TX (slip or slips or slipped or slipping or trip or trips or tripped or tripping)

S25 TX (stumble* or tumble*)

S26 TX lose footing

S27 S21 OR S22 OR S23 OR S24 OR S25 OR S26

S28 S20 AND S27

S29 (MH "Randomized Controlled Trials")

S30 (MH "Random Assignment")

S31 (MH "Clinical Trials")

S32 (MH "Control Group")

S33 (MH “Double-Blind Studies”) OR (MH “Single-Blind Studies”) OR (MH “Triple-Blind Studies”) OR (MH "Intervention Trials”)

OR (MH "Preventive Trials") OR (MH “Therapeutic Trials”)

S34 (MH "Placebos") OR (MH "Placebo Effect")

S35 (MH “Cross Sectional Studies") OR (MH “Crossover Design”) OR (MH “Multicenter Studies”) OR (MH “Experimental Studies”)

OR (MH "Multimethod Studies")

S36 (MH "Study Design") OR (MH "Research Methodology")

S37 (MH "Program Evaluation")

S38 (MH "Evaluation Research")

S39 PT randomised controlled trial

S40 TX randomised controlled trial

S41 PT controlled clinical trial

S42 TX controlled clinical trial

S43 PT (clinical trial or clinical trial phase i or clinical trial phase ii or clinical trial phase iii or clinical trial phase iv)

S44 PT multicenter study

S45 TX multicenter study

S46 PT (evaluation studies or comparative study)

S47 TX (evaluation studies or comparative study)

S48 TX random*

S49 TX controlled

S50 TX (trial* or stud*)

S51 S49 AND S50

S52 TX clinical $^{*}$ trial $^{*}$

S53 TX (control or treatment or experiment* or intervention)

S54 TX (group* or subject* or patient*)

S55 S53 AND S54

S56 TX (quasi-random* or quasi random* or pseudo-random* or pseudo random*)

S57 TX (multicenter or multicentre or therapeutic)

S58 TX (trial* or stud*)

S59 S57 AND S58

Interventions for preventing falls in people after stroke (Review)

Copyright $\odot 2013$ The Cochrane Collaboration. Published by John Wiley \& Sons, Ltd. 
S60 TX (control or experiment* or conservative)

S61 TX (treatment or therapy or procedure or manage*)

S62 S60 AND S61

S63 TX coin AND TX ( (flip or flipped or toss*))

S64 TX versus

S65 TX (cross-over or cross over or crossover)

S66 TX placebo*

S67 TX sham*

S68 TX (assign* or alternate or allocat* or counterbalance* or multiple baseline)

S69 TX controls

S70 TX treatment* AND TX order

S71 S52 OR S55 OR S56 OR S59 OR S62 OR S63 OR S64 OR S65 OR S66 OR S67 OR S68 OR S69 OR S70

S72 S28 AND S71

S73 S28 AND S71 Limiters - Human

\section{Appendix 4. PsycINFO search strategy}

S1 DE "Cerebrovascular Disorders" OR DE "Cerebrovascular Accidents"

S2 DE "Basal Ganglia"

S3 DE "Cerebral Ischemia" OR DE "Cerebral Small Vessel Disease"

S4 DE "Carotid Arteries"

S5 intracranial arterial disease*

S6 "intracranial embolism and thrombosis"

S7 intracranial embolism

S8 DE "Subarachnoid Hemorrhage" OR DE "Cerebral Hemorrhage"

S9 intracranial vasospasm

S10 DE "Brain Disorders"

S11 DE "Cerebral Arteriosclerosis"

S12 TX (stroke or poststroke or post-stroke or cerebrovasc* or brain vasc* or cerebral vasc* or cva* or apoplex* or SAH)

S13 TX (brain* or cerebr* or cerebell* or intracran* or intracerebral)

S14 TX (brain* ${ }^{*}$ or cerebr* or cerebell* ${ }^{*}$ or intracran* ${ }^{*}$ or intracerebral) AND TX (isch?emi* or infarct* ${ }^{*}$ or thrombo* or emboli* $^{*}$ or

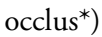

S15 TX (brain* or cerebr* or cerebell* or intracerebral or intracranial or subarachnoid) AND TX (haemorrhage* or hemorrhage* ${ }^{*}$ haematoma* or hematoma* or bleed*)

S16 DE "Hemiplegia" OR DE "Hemiparesis"

S17 TX (hemipleg* or hemipar* or paresis or paretic)

S18 TX neurologic gait disorder*

S19 S1 OR S2 OR S3 OR S4 OR S5 OR S6 OR S7 OR S8 OR S9 OR S10 OR S11 OR S12 OR S13 OR S14 OR S15 OR S16 OR

S17 OR S18

S20 DE "Falls"

S21 DE “Accidents" OR DE "Falls" OR DE "Home Accidents" OR DE "Industrial Accidents" OR DE "Pedestrian Accidents" OR

DE “Transportation Accidents" OR DE “Accident Prevention” OR DE “Home Accidents"

S22 DE “Accident Proneness"

S23 TX (fall or falls or faller or fallen or fallers or falling or fall-related or near-fall or falls-efficacy scale)

S24 TX (slip or slips or slipped or slipping or trip or trips or tripped or tripping)

S25 TX (stumble* or tumble*)

S26 TX lose AND TX footing

S27 S20 OR S21 OR S22 OR S23 OR S24 OR S25 OR S26

S28 S19 AND S27

S29 DE "Random Sampling"

S30 DE "Clinical Trials"

S31 DE "Experiment Controls"

Interventions for preventing falls in people after stroke (Review)

Copyright $\odot 2013$ The Cochrane Collaboration. Published by John Wiley \& Sons, Ltd. 
S32 DE "Double Bind Interaction"

S33 DE "Placebo"

S34 DE "Experimentation" OR DE "Experimental Methods"

S35 DE "Methodology"

S36 DE "Program Evaluation"

S37 DE "Followup Studies" OR DE "Longitudinal Studies" OR DE "Retrospective Studies"

S38 PT randomised controlled trial

S39 TX randomised controlled trial

S40 PT controlled clinical trial

S41 TX controlled clinical trial

S42 PT (clinical trial or clinical trial phase i or clinical trial phase ii or clinical trial phase iii or clinical trial phase iv)

S43 TX (clinical trial or clinical trial phase i or clinical trial phase ii or clinical trial phase iii or clinical trial phase iv)

S44 PT multicenter study

S45 TX multicenter study Search modes

S46 PT (evaluation studies or comparative study)

S47 TX (evaluation studies or comparative study)

S48 TX random*

S49 TX controlled AND TX (trial* or stud*)

S50 TX clinical* trial* $^{*}$

S51 TX (control or treatment or experiment* or intervention) AND TX (group* or subject* or patient*)

S52 TX (quasi-random* or quasi random* or pseudo-random* or pseudo random*)

S53 TX (multicenter or multicentre or therapeutic) AND TX (trial* or stud*)

S54 TX (control or experiment* or conservative) AND TX (treatment or therapy or procedure or manage*)

S55 TX coin AND TX (flip or flipped or toss*)

S56 TX versus

S57 TX (cross-over or cross over or crossover)

S58 TX placebo*

S59 TX sham

S60 TX (assign* or alternate or allocat* or counterbalance* or multiple baseline)

S61 TX controls

S62 TX treatment* AND TX order

S63 S29 OR S30 OR S31 OR S32 OR S33 OR S34 OR S35 OR S36 OR S37 OR S38 OR S39 OR S40 OR S41 OR S42 OR S43

OR S44 OR S 45 OR S 46 OR S 47 OR S48 OR S49 OR S50 OR S51 OR S52 OR S53 OR S54 OR S55 OR S56 OR S57 OR S58

OR S59 OR S60 OR S61 OR S62

S64 S28 AND S64

S65 S28 AND S64 Limiters - Population Group: Human

\section{Appendix 5. AMED search strategy}

1 Cerebrovascular disorders/

2 exp Basal ganglia/

3 exp Cerebral ischemia/

4 Carotid arteries/

5 intracranial embolism.mp.

6 Brain disease/

7 exp Cerebral infarction/

8 vasospasm.mp.

9 Vertebral artery/

10 Cerebrovascular accident/

11 (stroke or poststroke or post-stroke or cerebrovasc\$ or brain vasc\$ or cerebral vasc\$ or cva \$ or apoplex\$ or SAH).tw. 12 ((brain\$ or cerebr\$ or cerebell\$ or intracran\$ or intracerebral) adj5 (isch?emi $\$$ or infarct $\$$ or thrombo $\$$ or emboli $\$$ or occlus $\$)$ ).tw.

Interventions for preventing falls in people after stroke (Review)

Copyright @ 2013 The Cochrane Collaboration. Published by John Wiley \& Sons, Ltd. 
13 ((brain $\$$ or cerebr $\$$ or cerebell $\$$ or intracerebral or intracranial or subarachnoid) adj5 (haemorrhage $\$$ or hemorrhage $\$$ or haematoma $\$$ or hematoma $\$$ or bleed $\$)$ ).tw.

14 Hemiplegia/

15 (hemipleg\$ or hemipar\$ or paresis or paretic).tw.

16 gait disorders/

171 or 2 or 3 or 4 or 5 or 6 or 7 or 8 or 9 or 10 or 11 or 12 or 13 or 14 or 15 or 16

18 Accident prevention/ or Accidental falls/

19 accidents/

20 (fall or falls or faller or fallen or fallers or falling or fall-related or near-fall or falls-efficacy scale).tw.

21 (slip or slips or slipped or slipping or trip or trips or tripped or tripping).tw.

22 (stumble $\$$ or tumble $\$$ ).tw.

23 (lose adj5 footing).tw.

2418 or 19 or 20 or 21 or 22 or 23

2517 and 24

26 Randomized controlled trials/

27 Random allocation/

28 controlled clinical trials.mp.

29 control groups.mp.

30 clinical trials/

31 Double blind method/

32 single blind method/

33 Placebos/

34 placebo effect.mp.

35 cross-over studies.mp.

36 multicenter studies.mp.

37 therapies investigational.mp.

38 investigational therapies.mp.

39 Research design/

40 Program evaluation/

41 evaluation studies.mp.

42 randomised controlled trial.pt.

43 controlled clinical trial.pt.

44 (clinical trial or clinical trial phase i or clinical trial phase ii or clinical trial phase iii or clinical trial phase iv).pt.

45 multicenter study.pt.

46 (evaluation studies or comparative study).pt.

47 random\$.tw.

48 (controlled adj5 (trial\$ or stud\$)).tw.

49 (clinical\$ adj5 trial\$).tw.

50 ((control or treatment or experiment $\$$ or intervention) adj 5 (group $\$$ or subject $\$$ or patient $\$)$ ).tw.

51 (quasi-random\$ or quasi random\$ or pseudo-random\$ or pseudo random\$).tw.

52 ((multicenter or multicentre or therapeutic) adj5 (trial\$ or stud $\$))$.tw.

53 ((control or experiment $\$$ or conservative) adj5 (treatment or therapy or procedure or manage $\$)$ ).tw.

54 ( (singl\$ or doubl\$ or tripl\$ or trebl\$) adj5 (blind $\$$ or mask $\$)$ ).tw.

55 (coin adj5 (flip or flipped or toss\$)).tw.

56 versus.tw.

57 (cross-over or cross over or crossover).tw.

58 placebo\$.tw.

59 sham.tw.

60 (assign\$ or alternate or allocat\$ or counterbalance\$ or multiple baseline).tw.

61 controls.tw.

62 (treatment $\$$ adj6 order).tw.

6326 or 27 or 28 or 29 or 30 or 31 or 32 or 33 or 34 or 35 or 36 or 37 or 38 or 39 or 40 or 41 or 42 or 43 or 44 or 45 or 46 or 47 or 48 or 49 or 50 or 51 or 52 or 53 or 54 or 55 or 56 or 57 or 58 or 59 or 60 or 61 or 62

Interventions for preventing falls in people after stroke (Review)

Copyright $\odot 2013$ The Cochrane Collaboration. Published by John Wiley \& Sons, Ltd. 
6425 and 63

\section{CONTRIBUTIONSOFAUTHORS}

G Verheyden planned the review, worked with A Ashburn and finalised the planning of the review based on comments from $\mathrm{V}$ Weerdesteyn, R Pickering, D Hyndman, S Lennon and A Geurts.

G Verheyden and V Weerdesteyn independently screened all search results.

G Verheyden, V Weerdesteyn and S Lennon independently screened full-text papers, performed data extraction and risk of bias screening. A Ashburn also screened all full-text papers for eligibility.

R Pickering and G Verheyden performed data analysis.

G Verheyden wrote the draft of the review and revised the draft based on comments from V Weerdesteyn, R Pickering, D Hyndman, $S$ Lennon, A Geurts, and A Ashburn.

\section{DECLARATIONSOF INTEREST}

None known

\section{DIFFERENCES BETWEEN PROTOCOLANDREVIEW}

We decided to pool results for one specific type of intervention (i.e. exercises) from single, multiple and multifactorial interventions. However, we additionally reported a sensitivity analysis of single interventions only. Thus, trials were not specifically grouped as single, multiple or multifactorial interventions as specified in our protocol.

\section{NDEX TERMS}

\section{Medical Subject Headings (MeSH)}

Accidental Falls [* prevention \& control; statistics \& numerical data]; Alendronate [administration \& dosage]; Bone Density Conservation Agents [administration \& dosage]; Exercise; Eyeglasses; Randomized Controlled Trials as Topic; Stroke [*complications]; Vitamin $\mathrm{D}$ [administration \& dosage]; Vitamins [administration \& dosage]

\section{MeSH check words}

Female; Humans; Male 